\title{
JUROR JUDGMENTS ACROSS DESCRIPTION INCONSISTENCIES AND MULTIPLE IDENTIFICATIONS
}

\author{
A thesis submitted to \\ the Faculty of Graduate Studies and Research \\ in Partial Fulfillment of the requirements for the degree \\ Masters of Arts
}

by

Monica C. O’Neill

Department of Psychology

Carleton University

September 2009

Copyright @ 2009, Monica O’Neill 


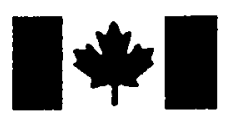

\author{
Library and Archives \\ Canada \\ Published Heritage \\ Branch \\ 395 Wellington Street \\ Ottawa ON K1A ON4 \\ Canada
}

Bibliothèque et

Archives Canada

Direction du

Patrimoine de l'édition

395 , rue Wellington

Ottawa ON K1A ON4

Canada
Your file Votre référence

ISBN: 978-0-494-58438-5

Our file Notre refférence

ISBN: 978-0-494-58438-5
NOTICE:

The author has granted a nonexclusive license allowing Library and Archives Canada to reproduce, publish, archive, preserve, conserve, communicate to the public by telecommunication or on the Internet, loan, distribute and sell theses worldwide, for commercial or noncommercial purposes, in microform, paper, electronic and/or any other formats.

The author retains copyright ownership and moral rights in this thesis. Neither the thesis nor substantial extracts from it may be printed or otherwise reproduced without the author's permission.
AVIS:

L'auteur a accordé une licence non exclusive permettant à la Bibliothèque et Archives Canada de reproduire, publier, archiver, sauvegarder, conserver, transmettre au public par télécommunication ou par l'Internet, prêter, distribuer et vendre des thèses partout dans le monde, à des fins commerciales ou autres, sur support microforme, papier, électronique et/ou autres formats.

L'auteur conserve la propriété du droit d'auteur et des droits moraux qui protège cette thèse. $\mathrm{Ni}$ la thèse ni des extraits substantiels de celle-ci ne doivent être imprimés ou autrement reproduits sans son autorisation.
In compliance with the Canadian Privacy Act some supporting forms may have been removed from this thesis.

While these forms may be included in the document page count, their removal does not represent any loss of content from the thesis.
Conformément à la loi canadienne sur la protection de la vie privée, quelques formulaires secondaires ont été enlevés de cette thèse.

Bien que ces formulaires aient inclus dans la pagination, il n'y aura aucun contenu manquant. 


\begin{abstract}
Mock jurors $(N=180)$ read a fictitious trial transcript that varied the consistency between the eyewitness' description of the criminal and the defendant ( 2 vs. 4 vs. 8 descriptor inconsistencies). Also, the consistency of the eyewitness' first lineup identification (ID) decision (positive vs. foil vs. non-) and a second lineup ID decision (positive) was manipulated. Mock jurors perceived the defendant as significantly more guilty, the eyewitness' description of the criminal as more reliable, the eyewitness' court ID as more reliable, and the eyewitness more positively overall when the eyewitness made few versus many descriptor inconsistencies. Mock jurors perceived the eyewitness' first lineup ID as significantly more reliable when the eyewitness initially made an accurate versus an inaccurate ID. There were no other significant effects of eyewitness ID on mock jurors' judgments, although trends of significance were identified. The limitations and implications of the present research are discussed.
\end{abstract}




\section{Acknowledgements}

First and foremost, I would like to thank my supervisor, Dr. Joanna Pozzulo, for her endless guidance, support, and mentorship throughout the completion of this thesis. I am truly grateful for your valuable knowledge, advice, and the countless hours you have spent encouraging me in times of doubt.

I would like to extend my appreciation to my committee members for their time, insightful feedback, and expertise. Also, thanks to my lab mates, Charmagne, Julie D., Julie L., Emily, and Alberta for your help and friendship.

To my family and friends, thank you for your love, support, patience, and encouragement throughout these past years. Most importantly, I would like to thank my mom and dad for being such wonderful and loving parents. Mom, thank you for the endless hours spent with me on the phone. You always found the time to listen and support me despite how busy you were.

Finally, I would like to thank Dave for his love, kindness, and understanding. Thank you for your ongoing patience, despite how busy I was or how many times I made you listen to my worries about school. I am truly blessed to have you in my life. 


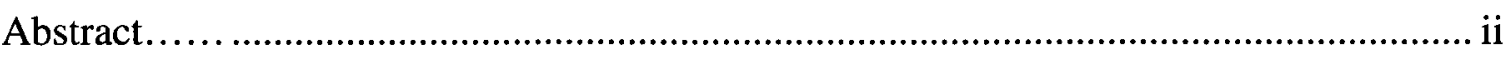

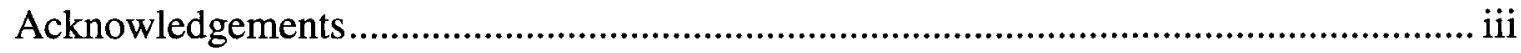

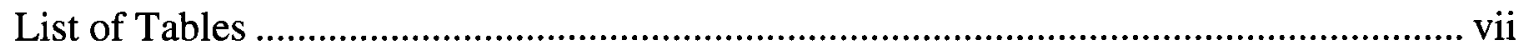

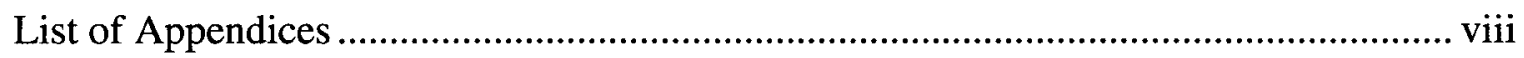

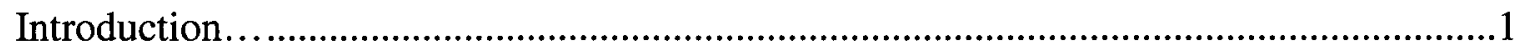

Juror Decision-Making Models .......................................................................

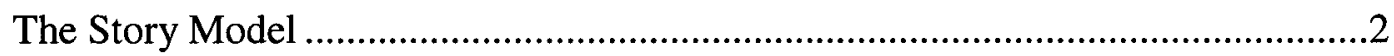

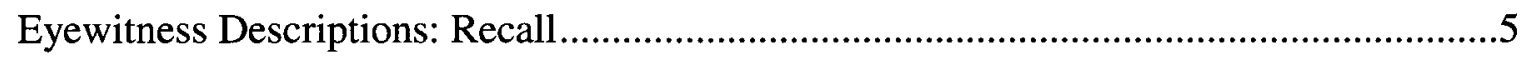

Quantity and Nature of Person Descriptions ...........................................6

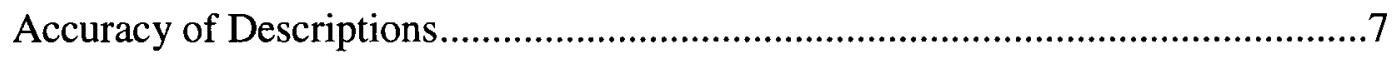

Juror Judgments: The Influence of Eyewitness Description Inconsistencies .........9

Eyewitness Identifications: Recognition.......................................................18

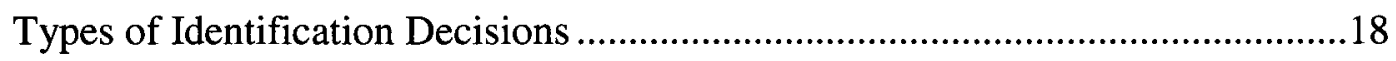

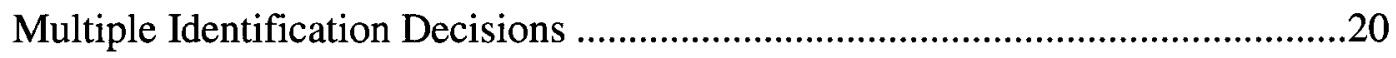

Juror Judgments: The Influence of Eyewitness Identification.........................21

The Relationship between Recall and Recognition .................................................31

Juror Judgments: Eyewitness Description Inconsistencies and Identification .......33

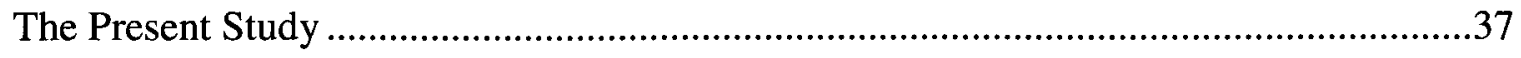


Participants

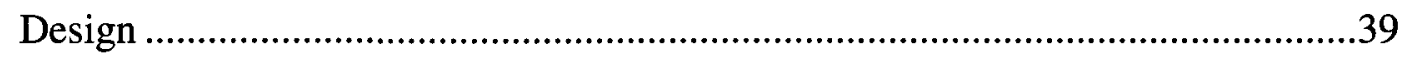

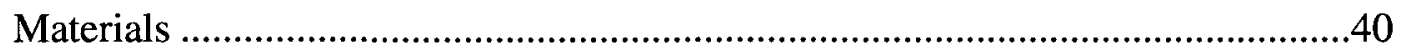

Trial transcript...................................................................40

Verdict form ..........................................................................40

Reliability, credibility, and accuracy ratings form................................4

Manipulation check form .............................................................4

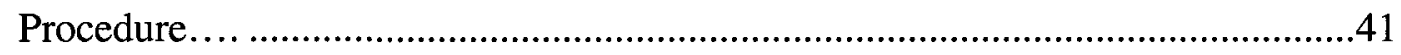

Results.................................................................43

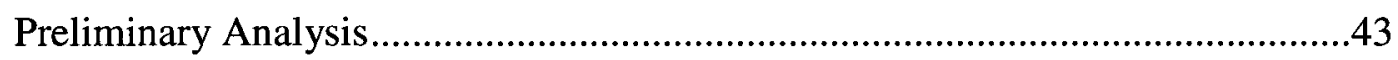

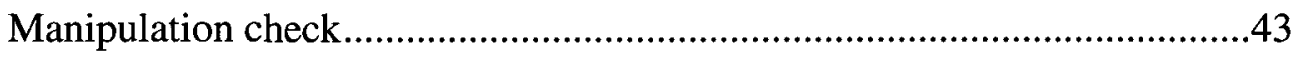

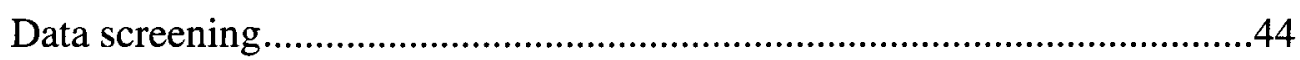

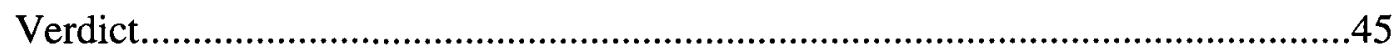

Continuous verdict ....................................................................45

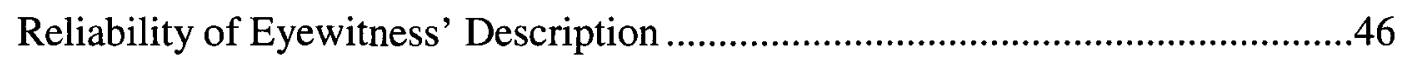

Reliability of Eyewitness' Identifications.................................................46

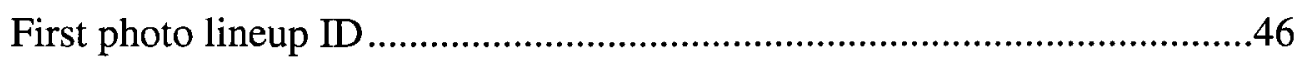

Second photo lineup ID ................................................................49

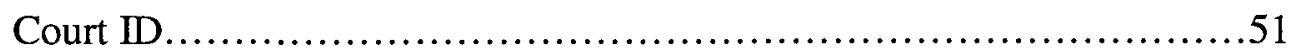




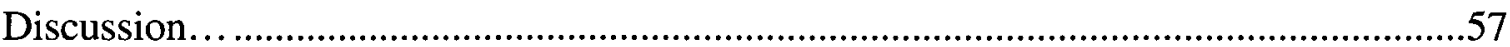

Eyewitness Descriptor Inconsistencies ................................................................57

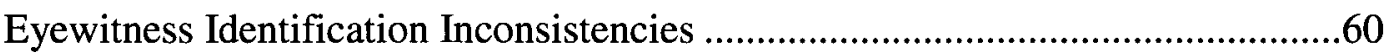

Limitations and Future Research ..................................................................65

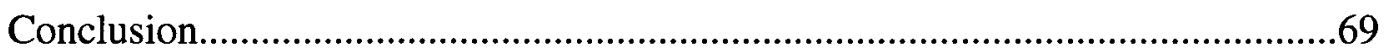

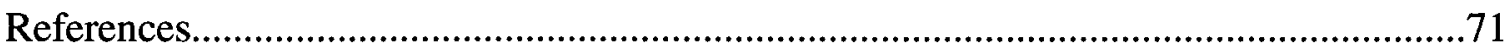

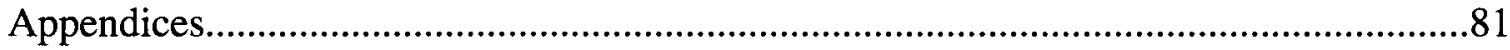




\section{List of Tables}

Table 1. Mock jurors' mean guilt ratings of the defendant as a function of eyewitness descriptor inconsistencies and ID

Table 2. Mock jurors' mean ratings of the eyewitness' overall description of the criminal as a function of eyewitness descriptor inconsistencies and ID

Table 3. Mock jurors' mean ratings of the reliability of the eyewitness' first photo lineup ID as a function of eyewitness descriptor inconsistencies and ID.....50

Table 4. Mock jurors' mean ratings of the reliability of the eyewitness' second photo lineup ID as a function of eyewitness descriptor inconsistencies and ID.....52

Table 5. Mock jurors' mean ratings of the eyewitness' ID of the defendant in court as a function of eyewitness descriptor inconsistencies and ID

Table 6. Correlations between the three questions assessing mock jurors' perceptions of the eyewitness overall.

Table 7. Mock jurors' mean ratings of the eyewitness overall as a function of eyewitness descriptor inconsistencies and ID..... 


\section{List of Appendices}

Appendix A. Trial Transcript............................................. 81

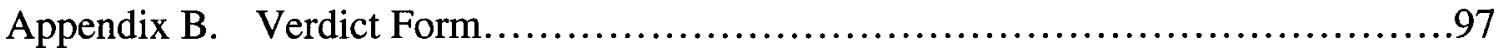

Appendix C. Reliability, Credibility, and Accuracy Ratings Form...................98

Appendix D. Manipulation Check Form..................................... 100

Appendix E. Informed Consent Form........................................ 102

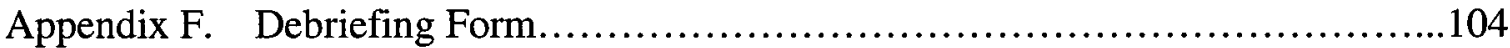


Juror Judgments across Description Inconsistencies and Multiple Identifications

In a criminal investigation, often eyewitnesses will undergo multiple interviews from various individuals (i.e., police investigators, attorneys, etc.). Throughout the investigation, eyewitnesses may change their stories or recall new information initially not remembered. Eyewitnesses also might be asked to make several identifications (IDs) throughout the investigation (e.g., $R$. v. Sophonow, 1986). Often jurors and judges are unaware of inconsistencies and/or multiple IDs when the eyewitness testifies in court. However, this knowledge could potentially influence jurors' decision-making. Therefore, the goal of the present study was to determine if knowledge of inconsistencies in the recall of criminal descriptors and eyewitness IDs will influence jurors' decisions.

\section{Juror Decision-Making Models}

A tremendous amount of juror research has been devoted to understanding the decision-making processes used by jurors. Although the intricacies of various juror decision-making models are not central to the present investigation, these models were fundamental to understanding how the present manipulations would influence mock jurors' decisions.

Traditional mathematical models (i.e., Information Integration, Bayesian, Poisson, Sequential Weighting), and explanation-based decision models (i.e., the Story Model) have been developed and employed to predict and explain juror decision-making (Pennington \& Hastie, 1986). Mathematical models, also termed as "meter models" (Lopes, 1993) theorize that jurors are constantly evaluating evidence presented and consequently updating a scale on the extent to which they perceive a defendant as guilty or not guilty (Lopes, 1993; McCullough, 2007). Although Pennington and Hastie (1986) 
admit that these models have enhanced our understanding of juror decision-making, they assert that these models neglect to consider jurors' cognitive representations of evidence and their reasoning about it. This view is further supported in a comprehensive review of mathematical models of juror decision-making where Ellsworth and Mauro (1998) claim that these models are deficient in their ability to consider the intrinsic value jurors assign to separate pieces of evidence. In contrast, Hastie and Pennington (2000) assert that the Story Model uniquely considers jurors' interpretation of the evidence as central to decision-making rather than merely a computation. Therefore, this explanation-based decision-making model was the model used to make hypotheses regarding the perceptions and decisions of mock jurors in the present investigation.

\section{The Story Model}

The Story Model is founded on the assumption that jurors construct stories using information presented during trial (Pennington \& Hastie, 1986, 1988, 1992) and that the story created influences jurors' subsequent verdict decisions (Hastie \& Pennington, 2000). The Story Model consists of three sequential stages including, story construction, verdict category establishment, and story classification, which will be discussed in the subsequent sections.

The story construction stage transpires throughout and following the presentation of trial information (Pennington \& Hastie, 1986). Three kinds of knowledge are central to jurors' cognitive representation of the evidence; specific information pertaining to the trial, prior knowledge of similar cases, and assumptions about the key components which complete a story (Pennington \& Hastie, 1992). Pennington and Hastie (1986) further assert that the narrative organization of the evidence occurs through knowledge about 
action sequences, termed an episode schema. Episode schemas are made of three interrelated components, the events that initiate an individual's psychological states and goals, reasons for the individual's succeeding actions, and the resulting outcome (Pennington \& Hastie, 1986). The individual's physical states are also central to the episode, such that when the initial events occur the individual's state facilitates succeeding actions, or the individual's state is a result of the initial events and thus is a factor triggering the individual's mental states or objectives. Episodes may also contain other episodes, resulting in a series of embedded episodes with the highest episode describing information that is central to what occurred (Hastie \& Pennington, 2000).

Jurors may construct one or multiple stories, and these stories can vary between jurors (Pennington \& Hastie, 1986). However, each story's coverage, coherence, uniqueness, and goodness-of-fit will determine which story is selected, jurors' subsequent verdict decisions, and their confidence in those decisions (Pennington \& Hastie, 1992). A story's coverage is determined by the amount of trial evidence that is incorporated into the story (Pennington \& Hastie, 1992). Coherence of a story is based on consideration of the story's completeness in which the story contains all key components, the story's consistency in which the story is not contradictory, and the story's plausibility, which is determined by evaluating story sequences against real world knowledge (Pennington \& Hastie, 1992). If jurors judge more than one story to be coherent, the story will lack uniqueness and uncertainty will result (Pennington \& Hastie, 1992).

The second stage, verdict category establishment, is where jurors learn and understand the verdict alternatives (Hastie \& Pennington, 2000; Pennington \& Hastie, 1986). This stage occurs at the closing of the trial when the judge provides jurors with 
instructions on the law (Pennington \& Hastie, 1986). The researchers propose that jurors create a cognitive representation of all of the verdict alternatives as categories that encompass several key components regarding identity, actions, circumstances, and mental state (Hastie \& Pennington, 2000; Pennington \& Hastie, 1986, 1988, 1992). For example, in the trial given to jurors in the present study, the defendant was charged with "attempt to commit murder" (Criminal Code, 1985). In order for jurors to find the defendant guilty of this charge, jurors would have to conclude that the evidence satisfied each criteria of that verdict (i.e., identity, actions, circumstances, and mental state). More specifically, jurors would have to conclude that the defendant is in fact the person who attempted to kill the victim (identity), the defendant shot the victim with a restricted or prohibited firearm (actions), the event occurred during the commission of the crime (circumstances), and the defendant shot the victim with the intention of causing an injury that could lead to death (mental state).

The final stage of the Story Model, story classification, refers to jurors determining the most correct match between the characteristics of the story previously constructed and the characteristics of each verdict category (Pennington \& Hastie, 1986). It is important to note however, that if there is only one uncertain issue in the trial (i.e., the identity of the criminal) jurors will only need to determine the match between the characteristics of the story constructed, and the characteristics of one potential verdict (Pennington \& Hastie, 1986). If the match between the story and the verdict(s) is inadequate then a default verdict of not guilty will be rendered (Pennington \& Hastie, 1992). Pennington and Hastie (1986) assert that the story classification process is facilitated by the correspondence between the key components of the verdict category 
(i.e., identity, actions, circumstances, and mental state) and the elements of an episode schema (i.e., initiating events, goals, actions, and accompanying physical and psychological states). The story classification stage also entails jurors' use of the judge's instructions regarding presumption of innocence and standard of proof (Pennington \& Hastie, 1986). Although the application of these instructions should be applied to each of the components of the verdict, Pennington and Hastie (1986) speculate that this is a global assessment. Jurors' confidence of the verdict decision made is a function of the story's coherence, coverage, uniqueness, and the goodness-of-fit between the story and verdict choice (Hastie \& Pennington, 2000).

Although the present study did not test the Story Model, it was used to examine the variables under investigation. The focus of the present study was to investigate the influence of eyewitness inconsistencies, with regards to both criminal descriptions and IDs, on mock jurors' decisions. The subsequent sections will provide a review of previous studies examining the influence of the present manipulations (eyewitness descriptor inconsistencies and ID) in order to hypothesize the results of the present study. Once a literature review of the relevant variables has been presented, the Story Model will be revisited to provide an additional explanation of the underlying processes that may occur when jurors are presented with eyewitness descriptor inconsistencies and ID.

\section{Eyewitness Descriptions: Recall}

An eyewitness describing what was "witnessed" is a recall task. In a criminal investigation, eyewitnesses are asked to describe what they saw during the crime in question. Eyewitnesses will be asked to report information regarding the context of the event (i.e., what happened, where the event occurred, etc.) and what the criminal(s) 
looked like (i.e., eye colour, clothing, tattoos, etc). Although both types of information are critical, the present study investigated the influence of eyewitness inconsistencies when recalling person descriptors on juror decision-making. Therefore, the present discussion will focus on person descriptions provided by an eyewitness.

\section{Quantity and Nature of Person Descriptions}

Various methodologies (i.e., archival, laboratory, and field) have been used to gain insight regarding the nature of criminal descriptions provided by eyewitnesses. In a recent comprehensive review of such studies, Meissner, Sporer, and Schooler (2007) assert that an eyewitness' person descriptions are often limited in detail and nondiscriminative. Laboratory studies involving staged crimes have reported that eyewitnesses provide an average of 9.38 (Ellis, Shepherd, \& Davies, 1980) and 7.35 (Lindsay, Martin, \& Webber, 1994) descriptor items. Wells (1993) contends that laboratory reports suggest that criminal descriptions consist of an average of 6 or 7 details and that this finding is mirrored by the average number of details reported in archival studies. In an archival study, Kuehn (1974) reported that on average participants recalled 7.2 details of the criminal. However, Lindsay et al. (1994) reported that on average 3.94 details were provided. In another analysis of archival data, van Koppen and Lochun (1997) reported that the completeness of eyewitness reports was inadequate, with a median of 8 details reported. In a more recent archival study, Fahsing, Ask, and Granhag (2004) reported that eyewitnesses provided 9.4 items, on average, when describing a criminal. It appears that between archival and laboratory studies the number of criminal details provided by an eyewitness will usually range from 7 to 10 descriptor items. 
Research investigations of archival data (Kuehn, 1974; Fahsing et al., 2004; Lindsay et al., 1994; van Koppen \& Lochun, 1997) have revealed that eyewitnesses tend to provide more general descriptions (e.g., sex, build, height, weight, age, race, and sometimes hair colour), compared to specific descriptions of the criminal (e.g., eye colour, nose shape). However, Lindsay et al. (1994) revealed that in laboratory studies using staged crimes often general features (e.g., gender, age, and race) are provided less frequently, while clothing and hair colour are reported more frequently. Additional laboratory studies (Ellis et al., 1980; Sporer, 1996) have cited hair items as those criminal descriptors most frequently reported by eyewitnesses. Both archival (Kuehn, 1974; Lindsay et al., 1994; van Koppen \& Lochun, 1997) and laboratory studies (Lindsay et al., 1994) however, have revealed that facial features (e.g., eye colour, nose, teeth) are reported much less frequently. Criminal descriptor items may also be categorized by permanence with either permanent (e.g. gender, race) or temporary (e.g., clothing, mask) items (van Koppen \& Lochun, 1997).

\section{Accuracy of Descriptions}

Researchers contend that eyewitnesses are, overall, accurate in their accounts of person descriptions, but again report few distinctive or identifying details (Fahsing et al., 2004; van Koppen \& Lochun, 1997; Yuille \& Cutshall, 1986). Although eyewitnesses appear to report sex with near perfect accuracy (Fahsing et al., 2004; van Koppen \& Lochun, 1997), other general features (i.e., height, weight, build, age) have been described with less accuracy (Fahsing et al., 2004; Pozzulo \& Warren 2003; Yarmey, 2004; Yarmey, Jacob, \& Porter, 2002; Yarmey \& Yarmey, 1997; Yuille \& Cutshall, 1986). Yuille and Cutshall found that in both police and research interviews, 
eyewitnesses only provided accurate estimates of height, weight, and age at chance level. Additionally, Flin and Shepherd (1986) reported that eyewitnesses would overestimate and underestimate the height and weight of below average and above average individuals, respectively. In other studies, eyewitnesses have reported age descriptions with high accuracy (97\%; Yarmey, 2004) and height and weight with moderate accuracy (Yarmey, 1993; Yarmey, 2004; Yarmey et al., 2002; Yarmey \& Yarmey, 1997). Findings have also varied with respect to eyewitness reports of hair descriptors. For example, several archival studies (van Koppen \& Lochun, 1997; Yuille \& Cutshall, 1986) have found that hair colour was reported with very high accuracy. Additionally, in a laboratory study, Pozzulo and Warren revealed that eyewitnesses reported hair colour and length most accurately. In contrast, field studies (Yarmey et al., 2002; Yarmey \& Yarmey, 1997) have found that hair colour has been reported with moderate or low accuracy relative to other studies. See Meissner et al. (2007) for a comprehensive review of the criminal descriptions provided by eyewitnesses.

In the present study the eyewitness provided 10 descriptor items (excluding the sex of the criminal given that this is generally reported with perfect accuracy) which included both general (i.e., age, weight, height) and specific (i.e., eye colour, nose shape, facial markings) items. An equal number of permanent and non-permanent descriptors were provided to ensure that the eyewitness descriptor inconsistency manipulation was not confounded because mock jurors reasoned that more or less inconsistencies were the result of the criminal changing his appearance rather than reflective of the eyewitness' memory. 


\section{Juror Judgments: The Influence of Eyewitness Description Inconsistencies}

Jurors have reported consistency as a major determinant of the accuracy of an eyewitness' testimony (Brewer, Potter, Fisher, Bond, \& Luszcz, 1999; Lindsay, 1994). For example, Lindsay had mock jurors rate the probability that an eyewitness' report would be accurate in a variety of circumstances. Two different samples of university students ranked the degree to which an eyewitness' description of the criminal was consistent with the appearance of the defendant appearing in court as one of the top indicators of eyewitness accuracy. This finding was supported by Brewer et al. where participants rated several eyewitness behaviours as indicative of inaccuracy.

Participants' ratings revealed that the behaviour believed to be the best indicator of eyewitness inaccuracy was when an eyewitness' statement was inconsistent with a previous statement made by that same eyewitness. Additionally, inconsistencies between eyewitnesses and recalling details previously not mentioned were also perceived as indicative of inaccuracy (Brewer et al., 1999).

Studies investigating the influence of eyewitness inconsistencies within a mock trial context have shown a significant influence of eyewitness inconsistencies on both mock jurors' verdicts and perceptions. Berman, Narby, and Cutler (1995) manipulated the consistency of the central and peripheral details reported by the prosecution's eyewitness. Inconsistencies were presented as contradictions between the eyewitness' pre-trial statements and current in-court statements. Central details entailed the criminal's appearance and involved the eyewitness' description of the criminal's facial hair, sunglasses, watch, and jacket colour. Peripheral details were items present in the eyewitness' surroundings that would not have been encoded by concentrating on the 
criminal's appearance and involved the eyewitness' description of the criminal's car model, what the criminal was carrying, the presence of a security guard, and the customer entering the bank with the criminal. Following the mock trial, jurors were asked to render a verdict (i.e., guilty vs. not guilty) and provide a rating of their perceptions of defendant culpability and the eyewitness overall. In the consistent conditions there were no inconsistencies between the two types of eyewitness statements.

Berman et al. (1995) revealed that mock jurors rated the eyewitness as significantly more credible, the defendant more culpable (although not statistically significant), and were more likely to convict when the eyewitness provided consistent versus inconsistent testimony. Although peripheral and central inconsistencies equally contributed to negative evaluations of the eyewitness, only central inconsistencies influenced verdict such that the defendant was significantly less likely to be convicted when the eyewitness provided central inconsistencies. Furthermore, individuals who voted guilty rated the eyewitness as significantly more consistent than those who voted not guilty.

Berman and Cutler (1996) examined how various types of eyewitness inconsistencies would influence mock jurors' decisions. In the consistent condition the eyewitness did not make any inconsistent statements. The three remaining conditions included a novel information condition in which details provided in court were not mentioned in the pretrial investigation, an on-the-stand pretrial contradiction condition in which inconsistent statements were made between court and in the pretrial investigation, and an on-the-stand contradiction condition in which inconsistent statements were made in court. Each inconsistency condition involved statements regarding the criminal's 
demeanor (nervous vs. calm), actions (if the criminal threatened the eyewitness, where the criminal placed the stolen money), and the criminal's appearance (jewelry). Following the mock trial, jurors were asked to provide dichotomous verdicts and rate their perceptions of defendant culpability and the effectiveness of the eyewitness.

The results (Berman \& Cutler, 1996) paralleled those of Berman et al. (1995) in which instances of inconsistency resulted in fewer guilty verdicts compared to instances where consistent testimony was provided. Additionally, the defendant was rated most culpable and the eyewitness most effective when the testimony was consistent, while significantly less so in the novel condition, and even significantly less in the two on-thestand-pretrial and on-the-stand contradictions, with no significant difference between the latter two conditions.

Berman and Cutler's (1996) findings were mirrored by Brewer and Hupfeld's (2004) more recent examination of eyewitness inconsistency on mock jurors' judgments. The eyewitness was either consistent throughout the trial or made a number of different inconsistent statements. In the inconsistent condition the eyewitness made one novel, two on-the-stand-pretrial, and two on-the stand contradictions. The eyewitness inconsistencies involved descriptions of distance, the criminal's handedness, clothing, verbal threats, and the description of blood. The researchers found that mock jurors rated the defendant as less culpable, the eyewitness as less effective, and rendered significantly fewer guilty verdicts when the eyewitness provided an inconsistent versus consistent testimony.

Although additional studies have found support for the influence of eyewitness inconsistencies on mock jurors' perceptions, they have failed to find a significant effect 
of such inconsistencies on mock jurors' verdict decisions (e.g., Lindsay, Lim, Marando, \& Cully, 1986). Lindsay et al. (1986) had a consistent condition where the eyewitness made no contradictory statements and an inconsistent condition where it was revealed that the eyewitness had initially described the criminal as having blond hair while the defendant had dark brown hair. The eyewitness testified "that she originally stated the criminal was blond, did not think the criminal could be described as blond, did not know if the defendant altered her hair colour between the time of the crime and the lineup procedure, recalled that the defendant's hair was dark when identified from the lineup, but still felt certain she had made an accurate ID" (Lindsay et al., 1986, p. 453). Following the trial, mock jurors rated the eyewitness' confidence, consistency, memory for central and peripheral details, and rendered dichotomous verdict decisions.

Despite finding that mock jurors were sensitive to the inconsistency manipulation, Lindsay et al. (1986) found no significant main effect of eyewitness inconsistency on mock jurors' dichotomous verdict decisions. Furthermore, guilty verdicts were actually somewhat higher in the inconsistent condition compared to the consistent condition. A follow-up analysis revealed that mock jurors who voted guilty perceived the eyewitness to be significantly more consistent, confident, and have a superior memory of the central and peripheral details, relative to mock jurors who voted not guilty.

There are many methodological issues to consider which may help explain Lindsay et al.'s (1986) failure to find a significant effect of eyewitness inconsistency on mock jurors' verdicts. One potential problem with the inconsistency manipulation is that the eyewitness claimed that she was certain she had made an accurate lineup ID decision. Mock juror research continually illustrates that mock jurors perceive an eyewitness as 
more accurate and render more guilty verdicts when the eyewitness exudes high versus low confidence (Culhane \& Hosch, 2004; Cutler, Penrod, \& Dexter, 1990; Cutler, Penrod, \& Stuve, 1988; Tetterton \& Warren; 2005; Wells, Lindsay, \& Ferguson, 1981). A more recent study (Brewer \& Burke, 2002) found evidence that eyewitness confidence nullified the effects of eyewitness inconsistency on mock jurors' decisions. Therefore, it is conceivable that although the mock jurors in Lindsay et al. (1986) were aware that the eyewitness was inconsistent, the eyewitness' high confidence nullified the effect of inconsistency on mock jurors' decisions.

Another shortcoming, is that the researchers only manipulated the consistency of one element (i.e., hair colour) of the eyewitness' testimony. Moreover, the eyewitness offered an explanation for this inconsistency by suggesting that the defendant could have changed her hair colour between the crime and her appearance in court. Perhaps if the eyewitness had made additional inconsistencies in the description of the criminal, the manipulation would have been more effective and any such explanations provided by the eyewitness would have been less convincing. This speculation is supported by the aforementioned studies that introduced jurors to a greater number of eyewitness descriptor inconsistencies and inconsistency types and yielded a significant effect of eyewitness inconsistencies on both mock jurors' verdicts and perceptions.

A more recent study (Semmler \& Brewer, 2002) also failed to find a significant effect of eyewitness inconsistencies on mock jurors' verdicts, but did find additional support that these inconsistencies influence mock jurors' perceptions. The eyewitness either made consistent statements throughout the trial or made inconsistent statements which were contradictory statements between the two prosecution eyewitnesses, and on- 
the-stand contradictions provided by one of the prosecution eyewitnesses. The eyewitness inconsistencies involved contradictory statements regarding the occurrence of events during a motor vehicle accident. Following the transcript, mock jurors' completed a series of measures including verdict, eyewitness credibility, defendant culpability, and a manipulation check examining jurors' perceptions of the consistency of the eyewitness' testimony and the processing of these inconsistencies.

Despite the evidence that mock jurors were sensitive to the inconsistency manipulation, there was no significant effect of eyewitness inconsistencies on mock jurors' verdicts. However, verdicts were in the expected direction, with less guilty verdicts in the inconsistent condition versus the consistent condition. Furthermore, there was a significant relationship between the processing of inconsistencies and mock jurors' judgments. As mock jurors' processing of inconsistencies increased their ratings of eyewitness credibility, defendant culpability, and guilty verdicts rendered decreased. Additionally, mock jurors rated the eyewitness as significantly less credible and the defendant as significantly less culpable in the inconsistent versus consistent condition.

The absence of a significant effect on mock jurors' verdicts is perhaps the result of the type of eyewitness inconsistencies provided. In the aforementioned inconsistency literature, there was always at least one inconsistency that involved the criminal's description. However, Semmler and Brewer (2002) explained that the main issue in the mock trial was whether a truck was on the wrong side of the road when a motor vehicle accident occurred, and thus the identity of the defendant was not an issue. Perhaps if identity had been an issue in the trial and some inconsistencies involved the description 
of the criminal, eyewitness inconsistency would have had a larger effect on mock jurors' verdicts.

The majority of the literature has revealed that eyewitness inconsistencies decrease mock jurors' ratings of eyewitness credibility and defendant culpability (Berman et al., 1995; Berman \& Cutler, 1996; Brewer \& Hupfeld; 2004; Semmler \& Brewer, 2002). Additionally, many investigations have indicated that eyewitness inconsistencies significantly decrease mock jurors' guilty verdicts (Berman et al., 1995; Berman \& Cutler, 1996; Brewer \& Hupfeld, 2002). Although, two studies (Lindsay et al., 1986; Semmler \& Brewer, 2002) failed to find a significant effect of eyewitness inconsistency on mock jurors' verdict decisions, there are several reasons to hypothesize that jurors' verdicts will be influenced by eyewitness inconsistency in the present study. Both studies (Lindsay et al., 1986; Semmler \& Brewer, 2002) revealed that mock jurors' who voted not guilty were significantly more likely to perceive the eyewitness as inconsistent compared to those who voted guilty. Also, it is likely that the high confidence exuded by the eyewitness and the fact that the manipulation of one descriptor item was weak could partially account for Lindsay et al.'s (1986) non-significant findings. The fact that Semmler and Brewer did not manipulate any eyewitness consistencies involving the criminal's face or appearance may also explain the study's non-significant effect of inconsistency on verdict. Furthermore, like Berman et al., the present study varied the number of criminal descriptor items that the eyewitness reports inconsistently, and thus the influence of eyewitness inconsistency on verdict should more closely parallel Berman et al.'s findings. 
The influence of eyewitness inconsistencies on mock jurors' judgments is further supported by the literature examining the effect of discrediting an eyewitness. Testimonial inconsistency has been identified as one of many factors contributing to jurors' perceptions of the credibility of an eyewitness (Boyce, Beaudry, \& Lindsay, 2007; Garcia \& Griffitt, 1978). Therefore, it is reasonable that testimonial inconsistencies are often brought to the attention of jurors, when a defence or prosecuting attorney is attempting to discredit an eyewitness.

Some studies have found that when information is presented to discredit an eyewitness, jurors may ignore this information (Cavoukian, 1980; Loftus, 1974). Jurors may also attempt to overcorrect for 'faulty' testimony and render verdicts in opposition to the original testimony as a form of retribution to the opposing side (prosecution or defence; Hatvany \& Strack, 1980; Sigler \& Couch, 2002). However, the majority of the literature has revealed that mock jurors disregard eyewitness testimony that has been discredited (Elliot, Farrington \& Manheimer, 1988; Hatvany \& Strack, 1980; Kennedy \& Haygood, 1992; Saunders, Vidmar, \& Hewitt, 1983; Weinberg \& Baron, 1982). The discrediting effect was further supported in a more recent meta-analysis of the previous credibility literature where Whitley (2001) reported that jurors rendered fewer guilty verdicts when an eyewitness was discredited compared to a non-discredited eyewitness. This research provides additional evidence that when an eyewitness is discredited in court by pointing out their inconsistent statements it will influence mock jurors' judgments.

In the present study, it was hypothesized that inconsistencies in criminal descriptors reported by the eyewitness would influence jurors' perceptions of the eyewitness' reliability, credibility, accuracy, and subsequent guilt ratings. Specifically, a 
transcript depicting an eyewitness making more versus less criminal descriptor inconsistencies will result in the eyewitness being perceived as less reliable, credible, and accurate, and lead to lower guilt ratings.

The Story Model also reinforces the hypothesis in the present study regarding the effect of inconsistent descriptions on mock jurors' decisions. As previously stated, jurors may construct one or more stories, but only one final story is selected and predicts the verdict decision (Pennington \& Hastie, 1986, 1988, 1992). One key factor influencing the story that is selected by jurors is the story's coherence, which includes consistency (Hastie \& Pennington, 2000; Pennington \& Hastie, 1986, 1988, 1992). A consistent story includes one which does not contain any contradictory evidence. Therefore, the inconsistent eyewitness evidence in the trial of the current study presents jurors with a predicament. Before jurors can select a consistent story, they must find a way to reconcile the inconsistencies that have been presented to them in the trial.

Pennington and Hastie (1988) have reported that the ease with which evidence is interpreted and a story is constructed for the prosecution versus the defence may influence jurors' verdict decisions. The researchers exposed participants to a trial where the stories of the prosecution and the defence were either easy or difficult to construct. Easy to construct stories were presented in story order, preserving the temporal order of the evidence. Difficult to construct stories were presented in eyewitness order, not preserving a temporal order of the evidence. As hypothesized, the researchers found that mock jurors were significantly more likely to render a guilty verdict when the prosecution presented evidence in the story order and the defence in the eyewitness order, compared to when the prosecution presented in the eyewitness order and the defence in 
the story order. Furthermore, evidence provided by the prosecution and defence were rated as stronger when presented in story order versus eyewitness order.

In the present study, the inconsistencies in the description of the criminal were committed by the prosecution's key eyewitness. Accordingly, it will likely be more difficult to construct a coherent story from the evidence presented by the prosecution than the defence. If this is the case, mock jurors should perceive the evidence presented by the prosecution (i.e., eyewitness reliability, accuracy, and credibility) as weaker than the evidence presented by the defence, and rate the defendant as less guilty. Furthermore, as the number of descriptor inconsistencies presented by the prosecution increases, the evidence presented by the prosecution will become more complicated to reconcile and it will be more difficult to construct a story for the prosecution relative to the defence. Accordingly, as the number of inconsistencies presented by the prosecution increases, the evidence presented by the prosecution will be perceived as increasingly weaker, and guilt ratings will decrease.

Eyewitness Identifications: Recognition

\section{Types of Identification Decisions}

An eyewitness providing a description of a criminal is a recall task, whereas an eyewitness identifying a criminal from a lineup is a recognition task. In a criminal investigation, eyewitnesses are often asked to examine a photo spread or lineup and identify the criminal of the crime in question. Wells and Lindsay (1980) identified three possible outcomes of an eyewitness lineup ID decision. The eyewitness makes a positive $I D$ in which the suspect is identified. The eyewitness makes a foil ID whereby an individual known to be innocent (e.g., a police officer) is identified. Alternatively, the 
eyewitness makes a non-ID in which the lineup is rejected and the eyewitness does not identify any of the individuals in the lineup as the criminal. These three different ID decisions differ in meaning depending on whether the suspect in the lineup is actually the criminal (i.e., the suspect is guilty). For example, the positive ID of a guilty suspect is a correct ID, which is an accurate decision. Additionally, a non-ID of a lineup where the suspect is innocent is considered a correct rejection, which is also an accurate decision. Any ID of a foil is a known error, which is an inaccurate decision. Thus, an ID of a suspect (i.e., a positive ID) may or may not be accurate. Also, the rejection of a lineup (i.e., a non-ID) may or may not be accurate.

Wells and Lindsay (1980) suggest that that the criminal justice system's treatment of non- or foil IDs as uninformative is likely the result of perceiving these ID decisions as indicative of memory failure. The researchers used Bayesian logic to challenge the criminal justice system's tendency to perceive a positive ID as highly informative, but overlooking a failure to identify the suspect (i.e., a foil or non- ID). Using the Bayesian model of information gain, the researchers asserted that if a positive ID increases the likelihood that the suspect is the criminal, then a non- or foil ID necessarily decreases the likelihood that the suspect is the criminal. Moreover, in some instances a non- or foil ID is more diagnostic regarding the guilt of the suspect compared to a positive ID. Further, the researchers suggest that the likelihood the defendant is not guilty is greater when the eyewitness makes a non- versus a foil ID. The Bayesian model has since been supported by other studies employing Bayesian statistics to illustrate the diagnosticity of eyewitness IDs (Clark, Howell, \& Davey, 2008; Levi, 1998; Lindsay \& Wells, 1980; Wells \& Luus, 1990; Wells \& Olson, 2002; Wells \& Turtle, 1986). 


\section{Multiple Identification Decisions}

In a criminal investigation, often multiple ID decisions are made when there is more than one eyewitness (Clark \& Wells, 2008; Sanders \& Warnick, 1982) or when an eyewitness is asked to view more than one lineup (Hinz \& Pezdek, 2001; Pezdek \& Blandon-Gitlin, 2005).

An eyewitness might be asked to view multiple lineups in various circumstances. For example, if the eyewitness identifies a foil, it is unlikely that this eyewitness would be asked to testify in court because he/she could not positively identify the defendant on trial. Additionally, the foil $\mathrm{ID}$ may indicate to the police investigators that the criminal is not in the lineup or that the eyewitness made a mistake. Police investigators may also make this assumption if the eyewitness makes a non-ID. As a result, eyewitnesses may be asked to look at a second lineup containing either the same suspect or a new suspect that has been apprehended due to new evidence. Afterward, the eyewitness testifies in court that the defendant was identified in the lineup (i.e., the suspect identified in the second lineup). Jurors, however, may be unaware that the eyewitness previously made an error (foil ID) or did not identify anyone (non-ID) when viewing the initial lineup.

Although the present study was not an investigation of ID decisions provided by multiple eyewitnesses, reference to the literature discussing the diagnosticity of multiple eyewitness IDs (Clark \& Wells, 2008; Sanders \& Warnick, 1982) may shed some light on the general implications when a single eyewitness provides multiple ID decisions. For example, if one eyewitness makes a positive ID and another eyewitness makes a non-ID, what is the probability that the suspect is guilty given the amalgamation of these decisions? 
Sanders and Warnick (1982) found that when unanimous ID decisions were provided they were most likely accurate, and when the decisions were conflicting the most common response was likely accurate. More recently, Clark and Wells (2008) found that the probability that the suspect was guilty increased when a positive ID was added to a previous positive ID. However, when a non-ID was added to a positive ID, the likelihood that the suspect was the true criminal was reduced. Also, the probability that the suspect was guilty, given a single positive ID, was decreased to a greater degree when a non-ID was provided compared to the increase incurred when another positive ID was added. The researchers also reported that the addition of a foil ID to a positive ID was more complex, such that it could increase and decrease the likelihood of guilt depending on the lineup composition (i.e., biased vs. non-biased). These findings provide a theoretical basis to believe that previous ID decisions (i.e., positive, foil, non-) will influence the perceived diagnosticity of a subsequent positive ID. More specific hypotheses regarding these ID combinations will be discussed in future sections. Juror Judgments: The Influence of Eyewitness Identification

Several investigations have examined the influence of eyewitness ID decisions (i.e., positive, foil, or non-) on mock jurors' decisions. The literature examines the influence of multiple IDs (provided by several eyewitnesses) on mock jurors' judgments. These findings were used to make hypotheses in the present study regarding the influence of multiple inconsistent ID decisions provided by a single eyewitness. Comparisons of the influence of different types of IDs also provides insight to how jurors perceive each type of ID relative to the other and which ID was likely to yield the greatest number of guilty verdicts and most favourable perceptions of the identifying eyewitness. There are 
some discrepancies in the literature regarding which ID decision (positive or non-) mock jurors assign more weight. The present discussion will attempt to account for these discrepancies in order to make hypotheses regarding the influence of eyewitness IDs in the present study.

Lindsay et al. (1986) presented a mock trial in which zero, one, or two eyewitnesses testified for the prosecution (i.e., positive ID) and zero, one, or two eyewitnesses testified for the defence (i.e., non-ID). In the positive ID condition, the eyewitness(es) testified that they had a clear view of the criminal and were certain that the defendant was the criminal. In the non-ID condition the eyewitness(es) testified that they had a clear view of the crime and were certain the defendant was not the criminal. Following the trial, mock jurors rendered a dichotomous verdict decision.

Lindsay et al. (1986) revealed that there were significantly more guilty verdicts when positive IDs were unopposed, less when eyewitness IDs were inconsistent, and fewer when non-IDs were unopposed, with significant differences between each situation. These findings suggest that in the present study when a single eyewitness makes two inconsistent ID decisions mock jurors will rate the defendant as significantly less guilty compared to when the eyewitness makes consistent ID decisions.

Lindsay et al. (1986) also found that the number of eyewitnesses testifying for the prosecution significantly influenced guilty votes, such that as more eyewitnesses provided a positive ID for the prosecution, guilty judgments increased. In contrast, when more eyewitnesses provided a non-ID for the defence, guilty judgments decreased. However, there was no significant difference in verdict decisions when one versus two eyewitnesses made a positive ID or when one versus two eyewitnesses made a non-ID. A 
significant difference between one and two non-IDs but not between one and two positive IDs would have indicated that it would take twice as many non-IDs to significantly decrease mock jurors' guilty verdicts. Therefore the non-significant difference between one and two positive IDs and non-IDs illustrates that mock jurors generally assigned similar weight to positive and non- IDs. Contrary to Wells and Lindsay's (1980) contention that mock jurors underutilize non-IDs, Lindsay et al. (1986) revealed that a positive ID increased the likelihood a guilty verdict was rendered, and a non-ID decreased the likelihood a guilty verdict was rendered.

Despite Wells and Lindsay's (1980) suggestion that mock jurors tend to underutilize non-IDs, several investigations of have revealed that mock jurors may actually give greater weight to a non-ID compared to a positive ID. Leippe (1985) presented potential jurors with a mock trial varying the types of ID decisions made by the eyewitness(es) in court, resulting in four separate ID conditions; one eyewitness made a positive ID, two eyewitnesses made a positive ID, one eyewitness made a positive ID and the other made a non-ID, two eyewitnesses made a positive ID and one eyewitness made a non-ID. Following the trial, mock jurors were asked to rate the strength of evidence and render a verdict.

Leippe (1985) found that mock jurors perceived the evidence as strongest when two eyewitnesses made a positive ID and weakest when one eyewitness made a positive ID and the other made a non-ID, with a significant difference between the two ID conditions. There were also significantly more guilty verdicts rendered in the conditions where one or two eyewitnesses made a positive ID compared to when one eyewitness made a positive ID and the other made a non-ID, or two eyewitnesses made a positive ID 
and one made a non-ID. These findings are congruent with those of Lindsay et al. (1986) and suggest that in the present study when a single eyewitness makes two inconsistent ID decisions (regardless if one is a positive ID) the eyewitness IDs will be perceived as less credible and lead to lower guilt ratings compared to when the eyewitness makes consistent ID decisions, or a single positive ID.

Leippe (1985) also noted that when two eyewitnesses made a positive ID, the conviction rate only slightly increased compared to when one eyewitness provided a positive ID. However, when one eyewitness made a positive ID and another made a nonID, the conviction rate was dramatically reduced. Further, guilty judgments reduced even more so when one eyewitness made a non-ID in contrast to two other positive IDs. Based on these findings Leippe suggested that despite previous theories, a non-ID may not be interpreted as evidence that the eyewitness has a faulty memory but rather the defendant is not guilty. However, Leippe speculated that perhaps the fact that the non-ID eyewitness "confidently" stated in court that the defendant was not the criminal, rather than simply being unable to identify the defendant, could explain for the large effect of non-IDs on mock jurors' decisions. Leippe reasoned that usually a non-ID eyewitness would not be able to testify in court and that perhaps the non-ID would have had less of an impact if the eyewitness did not testify. Accordingly, Leippe conducted a similar second experiment to compare two non-ID eyewitnesses, one who confidently stated the "defendant was not the man" and testified in court, and one who claimed that the lineup members did not look familiar and did not testify in court (i.e., this non-ID was noted by the defence attorney). 
As hypothesized, Leippe (1985) revealed that there were significantly more guilty verdicts when the less confident non-ID eyewitness did not testify in court compared to when the non-ID eyewitness confidently testified in court. It seems that a non-ID can reduce guilty verdicts, but this effect is more prominent when a non-ID is assertively stated in court.

McAllister and Bregman (1989) also provided evidence that non-IDs may have greater influence than positive IDs on mock jurors' decisions. Mock jurors were exposed to a mock trial summary where the eyewitness made one of three ID types; a positive ID in which the eyewitness claimed to be certain that the defendant was the robber, a non-ID in which the eyewitness claimed to be certain that the defendant was not the robber, and a control ID in which the eyewitness claimed to be uncertain whether the defendant was or was not the robber. After reading the transcript mock jurors were asked to render a dichotomous verdict decision, and rate the guilt of the defendant.

McAllister and Bregman (1989) revealed that when the eyewitness made a nonID jurors rendered significantly fewer guilty verdicts and rated the defendant as significantly less guilty compared to when the eyewitness made a positive or control ID. There was no significant difference in jurors' guilty votes or ratings when the eyewitness made a positive ID compared to the control ID. However, mock jurors' guilt decisions were in the expected direction with more guilty votes and higher ratings of guilt when the eyewitness made a positive versus a control ID.

McAllister and Bregman's (1989) findings were supportive of Leippe (1985), such that mock jurors' guilty verdicts were significantly reduced when an eyewitness made a non-ID compared to a positive ID. McAllister and Bregman (1989) also provided 
evidence that contrary to Wells and Lindsay's (1980) contention, in some circumstances mock jurors may underutilize positive IDs and assign more weight to non-IDs.

Mock juror research on the influence of eyewitness ID has also supported Wells and Lindsay's (1980) assertion that jurors tend to perceive positive IDs as more informative and underutilize non-IDs. McAllister and Bregman (1986) examined the influence of positive and non- IDs provided by single and multiple eyewitnesses. Mock jurors were exposed to one of six types of eyewitness ID evidence; a single positive ID in which one eyewitness testified the defendant was the criminal, a single non-ID in which one eyewitness testified the defendant was not the criminal, a control ID in which one eyewitness testified that he was unable to say if the defendant was or was not the criminal, an inconsistent multiple ID in which one eyewitness made a positive ID and one made a non-ID, multiple positive IDs, and multiple non-IDs. Following the mock trial, jurors were asked to provide a guilt rating and sentence recommendation.

McAllister and Bregman's (1986) finding regarding the multiple ID conditions (i.e., two positive IDs, two non-IDs, and two inconsistent IDs) lends insight to the present study regarding the influence of multiple inconsistent eyewitness IDs provided by the same eyewitness on mock jurors' judgments. Although significance tests were not reported, guilt ratings and sentence recommendations were highest when two eyewitnesses made positive IDs, lower when inconsistent IDs were made, and even lower when two non-IDs were made. Additionally, a single positive ID lead to more guilty verdicts and longer sentences than two inconsistent IDs.

McAllister and Bregman (1986) revealed that a single positive ID or multiple positive IDs lead to significantly higher guilt ratings and longer sentences than the 
control ID. In contrast, only multiple non-IDs lead to significantly lower guilt ratings and shorter sentences compared to the control ID. Additionally, comparisons of single and multiple positive ID(s) did not produce significantly different perceptions of guilt and longer sentences, although these measures were slightly higher in the multiple IDs condition. However, there were significantly lower guilt ratings and shorter sentences in the multiple non-IDs condition versus the single non-ID condition. The findings support previous theories that non-IDs are often underweighted by mock jurors (Wells \& Lindsay, 1980). The findings revealed that although there is no difference in the effect of one or two positive IDs, it seems to take twice as many non-IDs to significantly reduce mock jurors' perceptions of guilt.

The underweight assigned to non-IDs was further supported by the researchers' finding that the inconsistent ID condition was significantly different from the single nonID, but not significantly different from the single positive ID. McAllister and Bregman (1986) assert that if a positive ID and non-ID were provided equal weighting, then the two IDs in the inconsistent condition should have cancelled each other out. However, the considerable difference between the inconsistent IDs and single non-ID illustrate that participants ignored the non-ID in the inconsistent condition when it was pitted directly against the positive $\mathrm{ID}$, as if it was not even present.

Pozzulo, Lemieux, Wells, and McCuaig (2006) found additional support for Wells and Lindsay's (1980) contention that mock jurors underutilize both non- and foil IDs. In a portion of a mock trial an eyewitness testified that he had made one of three lineup $\mathrm{ID}$ decisions; a positive $\mathrm{ID}$, a non-ID, and a foil $\mathrm{ID}$. Following the trial, mock 
jurors were asked to render a dichotomous verdict decision, rate the reliability of the crime details reported by the eyewitness, and rate the credibility of the eyewitness.

Mock jurors were significantly more likely to render guilty verdicts and perceive the eyewitness $\mathrm{ID}$ decision as more reliable when the eyewitness made a positive ID compared to a non-ID. Although approaching significance, mock jurors did not render significantly more guilty verdicts when the eyewitness made a positive ID compared to a foil ID. However, mock jurors did perceive a positive ID as significantly more reliable than a foil ID. There was no significant difference in mock jurors' verdicts or perceptions of the reliability of the eyewitness ID when the eyewitness made a foil ID compared to a non-ID. Eyewitness ID had no significant effect on mock jurors' perceptions of the credibility of the eyewitness.

In general, Pozzulo et al.'s (2006) findings are congruent with aforementioned literature (Leippe, 1985; Lindsay et al., 1986; McAllister \& Bregman, 1986, 1989) such that a positive ID was found to significantly increase guilty verdicts whereas a non-ID significantly reduced guilty verdicts. The findings also lend support for previous evidence that a positive ID is perceived more favourably than a foil or non- ID. It is also of interest that there was no significant difference in verdicts or perceptions of the reliability of the eyewitness' ID when a foil versus a non-ID was made. This finding suggests that mock jurors believe that choosing someone from a lineup who is not guilty (foil ID) is the same as rejecting the lineup (non-ID). Perhaps mock jurors would perceive a difference between these ID decisions if it was revealed that the "true suspect" was either in or was not in the lineup when the eyewitness made a foil or non-ID. The 
influence of foil and non- IDs when the suspect is reportedly in or not in the lineup was investigated in the eyewitness ID manipulation of the present study.

Although Leippe (1985) and McAllister and Bregman (1989) found evidence that mock jurors perceive non-IDs as more informative, McAllister and Bregman (1986) and Pozzulo et al. (2006) found mock jurors may perceive positive IDs as more informative, whereas Lindsay et al. (1986) found evidence that mock jurors perceive positive and nonIDs as equally informative. Perhaps Leippe's finding that mock jurors rendered significantly more guilty verdicts when the eyewitness provided a less confident non-ID and did not testify in court than when the eyewitness confidently provided a non-ID in court, is a starting point to resolving the discrepancies in the literature. It is important to note that in each of the studies finding that mock jurors' perceived a non-ID as more informative (Leippe, 1985; McAllister \& Bregman, 1989) or at least as informative (Lindsay et al., 1986) compared to a positive ID, the eyewitnesses stated they were "confident" or "certain" the defendant was not the man. In the studies finding that mock jurors perceived a positive ID as more informative, the eyewitness either stated that the defendant was not the man (McAllister \& Bregman, 1986) or they did not choose anyone from the lineup (Pozzulo et al., 2006). Perhaps when an eyewitness confidently makes a non-ID mock jurors are less likely to perceive the $\mathrm{ID}$ as an error in memory. This raises the question, how would a non-ID influence mock jurors' decisions if it was clear that the non-ID was not an error? For example, if it is reported that the defendant was not present in the lineup when the eyewitness made a non-ID, mock jurors may be less likely to perceive the non-ID as an error. 
The present study examined how multiple IDs by the same eyewitness influences mock jurors' decisions. Theoretically mock jurors should perceive a positive ID (of the suspect who is also the defendant) or a non-ID (when the defendant is absent from the lineup) as equally credible. According to the multiple ID literature, mock jurors should also perceive multiple IDs where the eyewitness initially makes an ID error (i.e., positive ID of the suspect who is different than the defendant, foil ID where the suspect is in the lineup, foil ID where the defendant is not in the lineup, or non-ID where the defendant is in the lineup) as less credible even if these IDs are followed by a positive ID of the suspect who is the defendant. Therefore, it was hypothesized that in conditions where the eyewitness did not make any errors in ID (i.e., positive ID of a suspect who is the defendant, or a non-ID where the defendant is not in the lineup followed by a positive ID of a suspect who is also the defendant) the eyewitness would be perceived as more reliable, credible, accurate, and result in higher guilt ratings than conditions where the eyewitness made an error in ID (i.e., positive ID of a suspect who is different than the defendant, non-ID where the defendant was in the lineup, foil ID where the defendant was in the lineup, foil ID where the defendant was not in lineup) prior to being able to identify the suspect who is also the defendant.

The present hypothesis of the influence of eyewitness ID on mock jurors' decision-making is both supported by and in accordance with the Story Model. According to the final stage (story classification) of the Story Model, jurors must determine that the key components of the story constructed are congruent with those components of each verdict alternative (Pennington \& Hastie, 1986). The primary issue in the trial for the present study was the identity of the defendant. Conditions in the 
present study where the eyewitness has made errors in the ID task will cause uncertainty regarding the identity of the defendant. As a result, there will be an inadequate match between the story constructed and a guilty verdict for "attempt to commit murder" (Pennington \& Hastie, 1992). Therefore, the Story Model supports the hypothesis in the present study that conditions where the eyewitness does not make errors in ID will result in higher guilt ratings, relative to conditions where ID errors do occur thus resulting in lower guilt ratings.

The Relationship between Recall and Recognition An abundance of research has been devoted to investigating the relationship between the accuracy of eyewitnesses' descriptions (recall) and subsequent lineup ID accuracy (recognition; Goldstein, Johnson, \& Chance, 1979; Pigott \& Brigham, 1985; Pigott, Brigham, \& Bothwell, 1990; Pozzulo \& Warren, 2003; Sporer, 1989, 2007; Wells, 1985). Meissner et al. (2007) assert that despite the intuitive belief that eyewitnesses who provide better descriptions of the criminal should also be better able to identify the criminal, the research illustrates that this relationship is generally weak. The researchers attribute this weak relationship to the distinctive cognitive processes involved in recall versus recognition.

Some investigations of the eyewitness recall-recognition paradigm have found support for a positive relationship between recall and recognition (Mauldin \& Laughery, 1981; Pozzulo \& Warren, 2003; Read; 1979, Sporer, 1992, 1996). In contrast, studies of facial memory (Goldstein et al., 1979; Sporer, 1989) have failed to find a relationship between verbal descriptions of faces and the subsequent recognition of those faces. Additionally, eyewitness experiments have failed to find a relationship between the 
accuracy of eyewitness descriptions (recall) and lineup ID decisions (recognition; Pigott \& Brigham, 1985; Pigott et al., 1990).

Some studies have found evidence that verbal descriptions can actually have debilitating effects on subsequent recognition tasks, termed the "verbal overshadowing effect" (Dodson, Johnson, \& Schooler, 1997; Meissner \& Brigham, 2001; Schooler \& Engstler-Schooler, 1990). However, other studies have revealed that verbal descriptions may contribute to increasing the accuracy of subsequent recognition, termed "verbal facilitation" (Brown \& Lloyd-Jones, 2005, 2006; Itoh, 2005; Meissener, Brigham, \& Kelly, 2001). A recent meta-analysis (Meissner, Sporer, \& Susa, 2008) revealed a small, but significant relationship between eyewitness recall accuracy and ID accuracy. Specifically, there was a positive relationship between the number of accurate descriptions and ID accuracy, a positive relationship of the congruence between the description of the target and the target identified with ID accuracy, and a negative relationship between the number of incorrect descriptors provided and ID accuracy.

The recall-recognition literature also extends to the present study regarding the relationship between recalling inconsistent criminal descriptors and lineup ID accuracy. Fisher and Cutler (1995) examined the validity of eyewitness consistency as an indicator of ID accuracy by examining the consistency and accuracy of eyewitness descriptions. In a series of studies, the researchers had participants view a staged crime and answer questions regarding the criminal(s) shortly after, and then again after a longer period of time. Following the second description, participants viewed a target-present or -absent photo lineup and were asked to identify the criminal. Examinations of the correlation between consistency and accuracy of reports, accuracy of reports and ID accuracy, and 
consistency and ID accuracy, revealed weak relationships in each case. The researchers contend however, that consistency and accuracy must relate to some degree because an inconsistent response necessitates at least one inaccurate response.

Brewer et al. (1999) further reinforced the negligible relationship between consistency and accuracy. Participants viewed a video of a simulated robbery and answered a series of questions, via interview, shortly after having viewed the videotape and then again, two weeks following. The researchers found that a small amount of variance in accuracy was accounted for by consistency measures. The results of these studies provide little evidence of a relationship between accuracy and consistency. Therefore, the recall of criminal descriptors provided by an eyewitness, which are inconsistent with the defendant identified, are not necessarily an indication that the eyewitness was less accurate in their ID than an eyewitness who provided fewer or no inconsistencies in their descriptions. However, the following review on juror decisionmaking will illustrate that it is likely that mock jurors will perceive eyewitness ID decisions and descriptor inconsistencies as associated.

Juror Judgments: Eyewitness Description Inconsistencies and Identification

Recent studies have examined the influence of eyewitness inconsistencies in relation to other variables such as confidence (Brewer \& Burke, 2002; Tenney, MacCoun, Spellman, \& Hastie, 2007), mood (Semmler \& Brewer, 2002), group identity (Brewer \& Hupfeld, 2004), attractiveness (Lindsay et al., 1986), and eyewitness age (Leippe and Romanczyk, 1989). Eyewitness ID studies have also investigated the interaction between eyewitness ID and other variables including, timing of measure (i.e., pre- vs. post- deliberation), severity of sentence (Leippe, 1985), and eyewitness age 
(Pozzulo et al., 2006). However, the interaction between eyewitness ID and descriptor inconsistencies on juror decision-making has not yet been investigated, and thus potential interactions between the two variables can only be speculated on.

The literature examining the effect of eyewitness inconsistencies on mock jurors' decisions has yielded inconsistent findings. Some researchers have reported that mock jurors rendered significantly more guilty verdicts when the eyewitness provided consistent versus inconsistent testimony (Berman et al., 1995; Berman \& Cutler, 1996; Brewer \& Hupfeld, 2004), whereas others have failed to find a significant main effect of eyewitness inconsistencies on verdict (Lindsay et al., 1986; Semmler \& Brewer, 2002). Investigations of the interaction between eyewitness inconsistencies and other variables have also revealed that eyewitness inconsistencies do not always have a predominating effect. Leippe and Romanczyk (1989) found that mock jurors perceived the prosecution's case as stronger and the eyewitness as more credible when consistent relative to inconsistent testimony was provided, but this effect was only present when the eyewitness was in a specific age group. Brewer and Burke (2002) examined the effect of eyewitness inconsistencies and confidence on mock jurors' decisions and reported that confidence nullified the effects of eyewitness inconsistencies on mock jurors' decisions.

In contrast, the collection of studies examining the influence of eyewitness ID on mock jurors' decisions have consistently found a significant main effect of eyewitness ID on verdict, with no interactions (Leippe, 1985; Lindsay et al., 1986; McAllister \& Bregman, 1986, 1989; Pozzulo et al., 2006). For example, Pozzulo et al.'s examination of eyewitness ID and eyewitness age on mock jurors' decisions revealed only a significant main effect of eyewitness ID and no significant effect of eyewitness age on 
mock jurors' verdicts. Furthermore, the effect of eyewitness ID was not qualified by an interaction between the two variables under investigation. A similar pattern of findings was revealed when Leippe examined the interaction between eyewitness ID and several additional variables.

Given the findings that eyewitness ID consistently influences mock jurors' judgments and eyewitness inconsistencies may or may not influence mock jurors' judgments, often depending on the other variables under investigation, it is likely that eyewitness ID will have a predominating effect on mock jurors' judgments in the present study. Therefore, it was hypothesized that in the present study the extent to which mock jurors detect eyewitness inconsistencies would be dependent on the types of IDs (i.e., positive, foil, non-) made by the eyewitness. Specifically, if the eyewitness makes a positive $\mathrm{ID}$, mock jurors will perceive the eyewitness as more credible than when making a foil ID and therefore be more willing to overlook the eyewitness' inconsistencies. In contrast, when the eyewitness makes a foil ID (known error) mock jurors may search for more confirming evidence that the eyewitness is not credible and the influence of eyewitness inconsistencies on mock jurors' decisions will be heightened.

Previous sections discussed how each of the variables (i.e., eyewitness descriptor inconsistencies and ID) influence mock jurors' decisions in accordance with the Story Model. The Story Model can also be used to support and explain the hypotheses made regarding the interaction of these variables.

Pennington and Hastie (1988) found that the ease with which mock jurors are able to construct stories for the evidence presented by the defence versus the prosecution can influence verdicts rendered and jurors' perceptions of the strength of that evidence. This 
finding was used to make hypotheses about the influence of descriptor inconsistencies with respect to the Story Model. It was hypothesized that as the number of descriptor inconsistencies increased it would become more difficult to construct a coherent story for the prosecution, thus weakening the prosecution's evidence and resulting in lower guilt ratings.

The trial in the present study has only one impending issue, the identity of the defendant. Is the defendant actually the person who attempted to kill the victim? Therefore, jurors only need to determine if the story constructed matches with one particular verdict alternative, "attempt to commit murder." Previously it was suggested that errors in the eyewitness ID decision would reduce certainty regarding the identity of the defendant. This uncertainty could potentially make the match between the story constructed and the verdict alternative (attempt to commit murder) inadequate, resulting in a default verdict of not guilty (Pennington \& Hastie, 1992). Therefore, when the key eyewitness makes an accurate ID decision (positive ID of the suspect who is the defendant, or non-ID where the defendant is not in the lineup) jurors will be more certain of the identity of defendant and render higher guilt ratings compared to when the eyewitness makes an inaccurate ID (positive ID of the suspect who is different than the defendant, foil ID where the defendant is in/not in the lineup, non-ID where the defendant is in the lineup), resulting in lower guilt ratings.

Together, these explanations of the effects of the relevant variables can be used to explain potential interactions in the present study. When the eyewitness makes an error in ID (i.e., positive ID of the suspect who is different than the defendant, foil ID where the defendant is in/not in the lineup, and non-ID where the defendant is in the lineup), 
jurors will be uncertain regarding the guilt of the defendant. Additionally, when descriptor inconsistencies increase, mock jurors will have a difficult time constructing a coherent story for the prosecution, decreasing guilt ratings and the perceived strength of the prosecution's evidence. Therefore, while mock jurors' guilty verdict ratings will decline when an error in ID has been made, an increase in descriptor inconsistencies will decrease guilt ratings and influence perceptions of the reliability of the eyewitness because identity uncertainty will be present and story construction will be difficult. However, when the eyewitness makes an accurate ID decision (i.e., positive ID of the suspect who is the defendant, or non-ID where the defendant is not in the lineup) jurors will be less likely to question the identity of the defendant. In this case, inconsistent descriptions could also potentially weaken jurors' perception of the strength of the evidence and result in lower guilty ratings. However, an increasing number of descriptor inconsistencies should not have a dramatic effect on jurors' responses when the eyewitness has made an accurate ID, because the ID has not instilled any doubt upon jurors regarding the identity of the defendant, which is the larger issue at hand.

\section{The Present Study}

The purpose of the present study was to examine the influence of eyewitness descriptor inconsistencies and multiple eyewitness IDs on mock jurors' decisions. Our hypotheses for the effects of the manipulated variables are presented below.

1) It was hypothesized that there would be a main effect of eyewitness descriptor inconsistencies such that when the eyewitness reports fewer descriptor inconsistencies ( 2 or 4 descriptor inconsistencies) mock jurors will rate the defendant as more guilty, the eyewitness' overall description of the criminal as 
more reliable, the eyewitness' ID decisions as more reliable, and the eyewitness as more reliable, credible, and accurate overall compared to when the eyewitness reports more descriptor inconsistencies (8 descriptor inconsistencies).

2) It was hypothesized that there would be a main effect of eyewitness ID such that when there is no error in ID decisions (i.e., positive ID of the suspect who is the defendant, or a non-ID where the defendant is not in the lineup) mock jurors will rate the defendant as more guilty, the eyewitness' overall description of the criminal as more reliable, the eyewitness' ID decisions as more reliable, and the eyewitness as more reliable, credible, and accurate overall compared to when there is an error in ID (i.e., positive ID of the suspect who is different than the defendant, foil ID where the defendant is in/not in the lineup, or non-ID where the defendant is in the lineup).

3) It was hypothesized that there would be a significant interaction between eyewitness descriptor inconsistencies and ID on mock jurors' decisions. Mock jurors will rate the defendant as more guilty, the eyewitness' overall description of the criminal as more reliable, the eyewitness' ID decisions as more reliable, and the eyewitness as more reliable, credible, and accurate overall when the eyewitness makes no ID errors (i.e., positive ID of the suspect who is the defendant, or a non-ID where the defendant is not in the lineup). However, when an error in ID occurs (i.e., positive ID of the suspect who is different than the defendant, foil ID where the defendant is in/not in the lineup, non-ID where the defendant is in the lineup) jurors' ratings will decrease as the number of descriptor inconsistencies increase. 
Method

\section{Participants}

One hundred and eighty undergraduate students ( 71 men and 106 women, with gender not reported by 3 participants) were recruited from the psychology participant pool at Carleton University. All participants were 18 -years-old or above $(M=20.89, S D$ $=4.01$, range: $18-52$ years) in order to be jury eligible in Ontario (Juries Act, 1990). Over half of the participants $(56.5 \%)$ identified themselves as Caucasian, and $79.0 \%$ reported English was their primary language. Participants received course credit (1\%) for their participation.

\section{Design}

A 3 (eyewitness descriptor inconsistencies; 2 inconsistencies vs. 4 inconsistencies vs. 8 inconsistencies) x 6 (eyewitness ID; positive ID of the suspect who is the defendant vs. positive ID of the suspect who is different than the defendant vs. foil ID where the defendant is in the lineup vs. foil ID where the defendant is not in the lineup vs. non-ID where the defendant is in the lineup vs. non-ID where the defendant is not in the lineup) between-subjects factorial design was used. All eyewitnesses not making a positive ID of the defendant for their first ID were shown a second lineup where they identified the defendant. The dependent variables were verdict (continuous), reliability of the eyewitness' overall description of the criminal, reliability of the eyewitness' ID decisions (i.e., first photo lineup ID, second photo lineup ID, court ID) and eyewitness reliability, credibility, and accuracy overall. 


\section{Materials}

Trial transcript. Eighteen versions of an 8-page mock-trial transcript (see Appendix A) were created, varying the number of descriptor inconsistencies to the defendant and the type of lineup ID prior to identifying the defendant in court. All other details of the crime were held constant across the different transcript versions. Mock jurors were initially informed that the trial involved an attempted murder that occurred during a liquor store robbery. Each transcript began with the judge addressing the court. The judge informed the court of the charge against the defendant (Section 259(1) of the Criminal Code, Attempt to commit murder) and explained that the Crown has the burden of proving their case beyond reasonable doubt. Further, the judge informed mock jurors to listen to all of the evidence, decide the facts, and apply the law presented at the closing of the trial. Mock jurors were also informed that at the end of the trial they would be asked to render a verdict. The judge's instructions were followed by opening statements from the Crown and Defence attorneys, presentations of each witness and their subsequent cross-examinations, and closing statements by the attorneys. At the conclusion, the judge provided the law and gave instructions to the jury members.

Verdict form (continuous). Mock jurors were asked to rate the guilt of the defendant (see Appendix B), for the charge of attempt to commit murder (Section 239(1) of the Criminal Code), on a continuous scale from 1 (Not Guilty) to 100 (Guilty). Although dichotomous verdict is a more ecologically valid measure, continuous verdict ratings provided a more sensitive assessment of jurors' verdict decisions. ${ }^{1}$ It should be

\footnotetext{
' Mock jurors' provided a dichotomous verdict (Not Guilty vs. Guilty) when completing the dependent measures to obtain a more ecologically valid measure of verdict. However, the final data set $(n=10)$ was too small to obtain enough power to examine dichotomous verdict, thus this measure was dropped from the analysis.
} 
noted that mock jurors who did not provide a number, but responded "not guilty" or “guilty," were scored as 1 and 100, respectively.

Reliability, credibility, and accuracy ratings form. Using a 100-point scale (1 = Not to $100=$ Absolutely), mock jurors were asked to rate their perception of the degree of reliability of the eyewitness' description of the defendant and various ID decisions (see Appendix C). For example, "How reliable was the identification decision that Diane Johnson (the witness) made when given the first photo lineup, prior to testifying in court?" Additionally, mock jurors used the same scale to rate the overall reliability, credibility, and accuracy of the witness.

Manipulation check form. Mock jurors were given multiple choice questions to determine if they accurately recalled the number of inconsistencies in the eyewitness' description of the criminal and the ID decisions made by the eyewitness when shown the first photo lineup and second photo lineup (for those in the ID conditions where a second lineup was shown; see Appendix D). Following each multiple choice question, mock jurors were asked to provide a rating; either of the degree of consistency of the eyewitness' description to the defendant or the degree of accuracy of the eyewitness' ID decisions (depending on the previous multiple choice question) on a 100-point scale ( $1=$ Not to $100=$ Absolutely).

Procedure

Participants were tested in the laboratory in groups of up to 10 participants per session, but completed the study independently. Upon arrival, participants were randomly assigned to 1 of 18 conditions. Each participant was initially asked to read and sign an informed consent form (see Appendix E). Afterwards, participants were asked to read 1 
of 18 versions of the mock trial transcript. Participants were subsequently asked to complete a questionnaire including the dependent measures and a brief demographic inquiry (i.e., age, gender, ethnicity, and primary language). Once participants had returned the trial transcript and the questionnaire, they were asked to complete a final questionnaire (i.e., the manipulation check). Following the manipulation check, participants were debriefed (see Appendix F) and thanked for their participation. 


\section{Results}

\section{Preliminary Analysis}

Manipulation check. A Manipulation check containing multiple choice questions and 100-point rating scales was administered to mock jurors to ensure they were cognizant of the eyewitness description and ID manipulations specific to their transcript. The accuracy of mock jurors' responses to the multiple choice questions (questions 1, 3, \& 5) were scored correct or incorrect. For questions where mock jurors were asked to provide ratings on a continuous scale for the consistency of the eyewitness' description (question 2) and the eyewitness' ID accuracy (questions $4 \& 6$ ), the accuracy of mock jurors' responses were determined by a specific range. For the rating regarding consistency of the eyewitness' description, accuracy was determined by a 33-point range. If mock jurors read a transcript where the eyewitness reported 8 descriptor inconsistencies, a rating from 1 to 33 was scored as correct. If the eyewitness reported 4 or 2 descriptor inconsistencies, a rating from 34 to 66 , and 67 to 100 , respectively, were scored as correct. For the ratings regarding ID, the accuracy of mock jurors' responses was determined by a 50-point range. For the rating regarding the accuracy of the first ID decision, if mock jurors read a transcript where the eyewitness made an ID error (i.e., positive ID of the suspect who is different than the defendant, foil ID where the defendant is in/not in the lineup, non-ID where the defendant is in the lineup) a rating from 1 to 50 was scored as correct. If the eyewitness made an accurate ID (i.e., positive ID of the suspect who is the defendant, non-ID where the defendant is not in the lineup) a rating from 51 to 100 was scored as correct. Additionally, eyewitness ID conditions 2 to 6 were exposed to a second ID decision. In all instances the eyewitness made an accurate ID 
decision (i.e., positive ID of the suspect who is the defendant), and thus a rating from 1 to 50 was scored as incorrect, whereas a rating from 51-100 was scored as correct.

The percentage of correct responses to the questions in the manipulation check was calculated for each mock juror. Mock jurors who responded to less than 50\% of the questions correctly were dropped from the data set. Ninety-two percent $(n=240)$ of mock jurors answered the questions in the manipulation check at or above 50\%. The remaining $8 \%(n=20)$ of mock jurors scored below chance on the manipulation check and were dropped from the data set. An additional participant who was not jury eligible in Ontario (i.e., reportedly under 18-years-old) was also dropped from the data set.

Data screening. The data set was checked for data entry errors, missing data, and outliers. The final data set used in the results analysis contained 10 participants per cell $(N=180)$.

It is believed that the assumptions (i.e., normality, independence of errors, and homogeneity of variance) were satisfied in each statistical model in the present study. The assumption of normality was satisfied given that there were equal sample sizes within each cell $(n=10)$, tests were two-tailed, and the degrees of freedom for error was well above $20\left(d f_{\text {error }}=162\right.$, or 135 ; Tabachnick $\&$ Fidell, 2007). Additionally, tests of skewness and kurtosis for each variable did not reveal values that substantially deviated from zero. Independence of errors was satisfied given that conditions were randomized, and experimental control was implemented (i.e., all participants were given identical instructions, tested in the same environment, responded independently, etc.). Levene's test of homogeneity of variance was assessed for each of the models in the present study. With one exception, Levene's did not reveal a violation of the assumption of 
homogeneity of variance. Tabachnick and Fidell have reported that analysis of variance (ANOVA) is robust to this assumption when outliers are absent, cell sizes are equal, and a two-tailed hypothesis is tested. Given that these conditions were present, and Levene's has been criticized for oversensitivity to heterogeneity of variance (Tabachnick \& Fidell, 2007), the single instance where the assumption of homogeneity of variance appeared to be violated was ignored.

\section{Verdict}

Continuous verdict. A 3 (eyewitness descriptor inconsistencies) x 6 (eyewitness ID) between-subjects ANOVA was conducted on mock jurors' ratings of the guilt of the defendant. There was a significant main effect for eyewitness descriptor inconsistencies, $F(2,162)=4.81, p<.01$, partial $\eta^{2}=.06,1-\beta=.79$, and a significant main effect for eyewitness $\mathrm{ID}, F(5,162)=3.13, p=.01$, partial $\eta^{2}=.09,1-\beta=.87$. No significant interaction between eyewitness descriptor inconsistencies and ID was found.

Tukey's HSD post hoc comparisons examined the effect of eyewitness descriptor inconsistencies on mock jurors' continuous verdicts. A Bonferroni correction $(p<.02)$ was made for the number of post hoc comparisons examining the effect of eyewitness descriptor inconsistencies on mock jurors' continuous verdicts. Mock jurors rated the defendant as significantly more guilty when the eyewitness' description contained 2 versus 8 descriptor inconsistencies (mean diff $=14.63, p=.02$ ) and 4 versus 8 descriptor inconsistencies (mean diff $=15.02, p=.02)$. A Bonferroni correction $(p<.003)$ also was made to correct for the number of post hoc comparisons examining the effect of eyewitness ID on mock jurors' continuous verdicts. There were no significant differences between the levels of eyewitness ID on mock jurors' ratings of the guilt of the 
defendant. See Table 1 for mock jurors' mean guilt ratings of the defendant as a function of eyewitness descriptor inconsistencies and ID.

\section{Reliability of Eyewitness' Description}

A 3 (eyewitness descriptor inconsistencies) x 6 (eyewitness ID) between-subjects ANOVA was conducted on mock jurors' ratings of the reliability of the eyewitness' overall description of the criminal. There was a significant main effect of eyewitness descriptor inconsistencies, $F(2,162)=24.89, p<.001$, partial $\eta^{2}=.24,1-\beta=1.00$. There was no significant main effect of eyewitness ID and no significant interaction between eyewitness descriptor inconsistencies and ID.

Tukey's HSD post hoc comparisons revealed that mock jurors rated the eyewitness' overall description of the criminal as significantly (Bonferroni correction, $p<$ .02) more reliable when the eyewitness reported 2 versus 8 descriptor inconsistencies (mean diff $=25.22, p<.001)$ and 4 versus 8 descriptor inconsistencies (mean diff $=$ $19.47, p<.001)$. No other significant differences were found. See Table 2 for mock jurors' mean ratings of the eyewitness' overall description of the criminal as a function of eyewitness descriptor inconsistencies and ID.

\section{Reliability of Eyewitness' Identifications}

First photo lineup ID. A 3 (eyewitness descriptor inconsistencies) x 6

(eyewitness ID) between-subjects ANOVA was conducted on mock jurors' ratings of the reliability of the eyewitness' first photo lineup ID. There was a significant main effect found for eyewitness $\operatorname{ID} F(5,162)=18.47, p<.001$, partial $\eta^{2}=.36,1-\beta=1.00$. There was no main effect of eyewitness descriptor inconsistencies or an interaction between eyewitness descriptor inconsistencies and ID found. 


\section{Table 1}

Mock jurors' mean (SE) guilt ratings of the defendant as a function of eyewitness descriptor inconsistencies and ID.

\section{Guilt Ratings}

Eyewitness Descriptor Inconsistencies

2 Descriptor Inconsistencies

$51.60(3.91)^{\mathrm{a}}$

4 Descriptor Inconsistencies

$51.98(3.91)^{\mathrm{a}}$

8 Descriptor Inconsistencies

$36.97(3.91)^{\mathrm{b}}$

Eyewitness ID

Positive ID (suspect same as defendant)

Positive ID (suspect different than defendant)

Foil ID (defendant in lineup)

Foil ID (defendant not in lineup)

Non-ID (defendant in lineup)

$38.10(5.52)$

Non-ID (defendant not in lineup)

$59.30(5.52)$

Note. Means under the eyewitness descriptor inconsistencies heading that do not share the same subscript differ at $p<.02$ in Tukey's HSD post hoc comparisons. 


\section{Table 2}

Mock jurors' mean ( $S E$ ) ratings of the eyewitness' overall description of the criminal as a function of eyewitness descriptor inconsistencies and ID.

Overall Description

Reliability

Eyewitness Descriptor Inconsistencies

2 Descriptor Inconsistencies

$70.58(2.65)^{\mathrm{a}}$

4 Descriptor Inconsistencies

$64.83(2.65)^{\mathrm{a}}$

8 Descriptor Inconsistencies

$45.37(2.65)^{b}$

Eyewitness ID

Positive ID (suspect same as defendant)

$66.67(3.75)$

Positive ID (suspect different than defendant)

$60.03(3.75)$

Foil ID (defendant in lineup)

$58.00(3.75)$

Foil ID (defendant not in lineup)

Non-ID (defendant in lineup)

Non-ID (defendant not in lineup)

$67.00(3.75)$

Note. Means under the eyewitness descriptor inconsistencies heading that do not share the same subscript differ at $p<.001$ in the Tukey's HSD post hoc comparisons. 
Tukey's HSD post hoc comparisons revealed that mock jurors perceived the eyewitness as significantly (Bonferroni correction, $p<.003$ ) more reliable when making a positive ID of the suspect who is the defendant versus a foil ID where the defendant is in the lineup (mean diff $=40.67, p<.001$ ), a foil ID where the defendant is not in the lineup (mean diff $=38.03, p<.001$ ), or a non-ID where the defendant is in the lineup (mean diff $=35.73, p<.001)$. A non-ID where the defendant is not in the lineup was perceived as significantly more reliable compared to a foil ID where the defendant is in the lineup (mean diff $=42.30, p<.001$ ), a foil ID where the defendant is not in the lineup (mean diff $=39.67, p<.001$ ), or a non-ID where the defendant is in the lineup (mean diff $=37.37, p<.001$ ). No other significant differences were found. See Table 3 for mock jurors' mean ratings of the reliability of the eyewitness' first photo lineup ID as a function of eyewitness descriptor inconsistencies and ID.

Second photo lineup ID. A second between-subjects ANOVA was conducted to determine the effect of eyewitness descriptor inconsistencies and ID on mock jurors' ratings of the eyewitness' second photo lineup ID (i.e., a positive ID of the suspect who is the defendant) after previously providing a different ID decision. The eyewitness ID control condition (positive ID of the suspect who is the defendant) was not followed by the second lineup ID to maintain ecological validity. Therefore, the following analysis discounted the eyewitness ID control condition.

A 3 (eyewitness descriptor inconsistencies; 2 inconsistencies vs. 4 inconsistencies vs. 8 inconsistencies) x 5 (eyewitness ID; positive ID of the suspect who is different than the defendant vs. foil ID where the defendant is in the lineup vs. foil ID where the defendant is not in the lineup vs. non-ID where the defendant is in the lineup vs. non-ID 
Table 3

Mock jurors' mean ratings $(S E)$ of the reliability of the eyewitness' first photo lineup ID as a function of eyewitness descriptor inconsistencies and ID.

First ID Reliability

Eyewitness Descriptor Inconsistencies

2 Descriptor Inconsistencies

4 Descriptor Inconsistencies

8 Descriptor Inconsistencies

Eyewitness ID

Positive ID (suspect same as defendant)

$59.37(4.46)^{\mathrm{a}}$

Positive ID (suspect different than defendant)

$35.20(4.46)^{\mathrm{ab}}$

Foil ID (defendant in lineup)

$18.70(4.46)^{\mathrm{b}}$

Foil ID (defendant not in lineup)

$21.33(4.46)^{\mathrm{b}}$

Non-ID (defendant in lineup)

$23.63(4.46)^{\mathrm{b}}$

Non-ID (defendant not in lineup)

$61.00(4.46)^{\mathrm{a}}$

Note. Means under the eyewitness ID heading that do not share the same subscript differ at $p<.001$ in Tukey's HSD post hoc comparisons. 
where the defendant is not in the lineup) between-subjects ANOVA was conducted on mock jurors' ratings of the reliability of the eyewitness' second photo lineup ID. There was a significant main effect of eyewitness ID on mock jurors' ratings of the reliability of the eyewitness' second photo lineup $\mathrm{ID}, F(4,135)=2.59, p=.04$, partial $\eta^{2}=.07,1-\beta=$ .72. No significant main effect of eyewitness descriptor inconsistencies or interaction between eyewitness descriptor inconsistencies and ID was found.

Tukey's HSD post hoc comparisons revealed that there were no significant (Bonferroni correction, $p<.005$ ) differences between eyewitness ID levels on mock jurors perceptions of the reliability the eyewitness' second photo lineup ID. See Table 4 for mock jurors' mean ratings of the reliability of the eyewitness' second photo lineup ID as a function of eyewitness descriptor inconsistencies and ID.

Court ID. A 3 (eyewitness descriptor inconsistencies) x 6 (eyewitness ID) between-subjects ANOVA was conducted on mock jurors' ratings of the reliability of the eyewitness' ID of the defendant in court. There was a significant main effect of eyewitness descriptor inconsistencies on mock jurors' perceptions of the reliability of the eyewitness' ID of the defendant in court, $F(2,162)=7.61, p<.01$, partial $\eta^{2}=.09,1-\beta$ $=.94$. No significant main effect of eyewitness ID or interaction between eyewitness descriptor inconsistencies and ID was found.

Tukey's HSD post hoc comparisons revealed that mock jurors rated the eyewitness' ID of the defendant in court as significantly (Bonferroni correction, $p<.02$ ) more reliable when the eyewitness reported 2 versus 8 descriptor inconsistencies (mean $\operatorname{diff}=17.07, p<.01)$ or 4 versus 8 descriptor inconsistencies $($ mean $\operatorname{diff}=16.37, p<.01)$. No other significant differences were found. See Table 5 for mock jurors' mean ratings 
Table 4

Mock jurors' mean (SE) ratings of the reliability of the eyewitness' second photo lineup

ID as a function of eyewitness descriptor inconsistencies and ID.

Second ID Reliability

Eyewitness Descriptor Inconsistencies

2 Descriptor Inconsistencies

4 Descriptor Inconsistencies

$52.06(3.78)$

8 Descriptor Inconsistencies

$45.40(3.78)$

Eyewitness ID

Positive ID (suspect different than defendant)

$48.80(4.88)$

Foil ID (defendant in lineup)

$49.07(4.88)$

Foil ID (defendant not in lineup)

$48.73(4.88)$

Non-ID (defendant in lineup)

$40.93(4.88)$

Non-ID (defendant not in lineup)

62.67 (4.88) 


\section{Table 5}

Mock jurors' mean $(S E)$ ratings of the eyewitness' ID of the defendant in court as a function of eyewitness descriptor inconsistencies and ID.

Court ID Reliability

Eyewitness Descriptor Inconsistencies

2 Descriptor Inconsistencies

$63.20(3.50)^{\mathrm{a}}$

4 Descriptor Inconsistencies

$62.50(3.50)^{\mathrm{a}}$

8 Descriptor Inconsistencies

$46.13(3.50)^{\mathrm{b}}$

Eyewitness ID

Positive ID (suspect same as defendant)

Positive ID (suspect different than defendant)

Foil ID (defendant in lineup)

Foil ID (defendant not in lineup)

Non-ID (defendant in lineup)

$53.20(4.95)$

Non-ID (defendant not in lineup)

$66.67(4.95)$

Note. Means under the eyewitness descriptor inconsistencies heading that do not share the same subscript differ at $p<.01$ in Tukey's HSD post hoc comparisons. 
of the reliability of the eyewitness' ID of the defendant in court as a function of eyewitness descriptor inconsistencies and ID.

\section{Eyewitness Ratings Overall}

Mock jurors were asked to rate the eyewitness on three different characteristics (i.e., overall reliability of testimony, overall accuracy, overall credibility) in order to assess their perceptions of the eyewitness overall. There was a significant correlation between the three questions (Cronbach's $\alpha=.95$ ) and thus a composite score for mock jurors' perception of the eyewitness overall was calculated. See Table 6 for the correlations between the three questions.

A 3 (eyewitness descriptor inconsistencies) x 6 (eyewitness ID) between-subjects ANOVA was conducted on the composite score of mock jurors' perceptions of the eyewitness overall. There was a significant main effect of eyewitness descriptor inconsistencies, $F(2,162)=11.30, p<.001$, partial $\eta^{2}=.12,1-\beta=.99$ and a significant main effect of eyewitness $\mathrm{ID}, F(5,162)=5.02, p<.001$, partial $\eta^{2}=.13,1-\beta=.98$. No significant interaction between eyewitness descriptor inconsistencies and ID was found. Tukey's HSD post hoc comparisons revealed that mock jurors rated the eyewitness as significantly (Bonferroni correction, $p<.02$ ) higher overall when the eyewitness' description contained 2 versus 8 descriptor inconsistencies (mean diff $=$ $16.64, p<.001$ ), and 4 versus 8 descriptor inconsistencies (mean diff $=14.77, p<.001)$. There was no significant (Bonferroni correction, $p<.003$ ) difference between eyewitness ID levels on mock jurors' ratings of the eyewitness overall. See Table 7 for mock jurors' mean ratings of the eyewitness overall as a function of eyewitness descriptor inconsistencies and ID. 
Table 6

Correlations between the three questions assessing mock jurors' perceptions of the eyewitness overall.

\begin{tabular}{lcc}
\hline Reliability & Credibility & Accuracy \\
\hline Reliability & $.88^{*}$ & $.89 *$ \\
Credibility & & $.83^{*}$ \\
\hline
\end{tabular}

$* p<.01$. 


\section{Table 7}

Mock jurors' mean (SE) ratings of the eyewitness overall as a function of eyewitness descriptor inconsistencies and ID.

Eyewitness Ratings

Overall

Eyewitness Descriptor Inconsistencies

2 Descriptor Inconsistencies

$62.89(2.71)^{\mathrm{a}}$

4 Descriptor Inconsistencies

$61.03(2.71)^{\mathrm{a}}$

8 Descriptor Inconsistencies

$46.26(2.71)^{\mathrm{b}}$

Eyewitness ID

Positive ID (suspect same as defendant)

Positive ID (suspect different than defendant)

Foil ID (defendant in lineup)

Foil ID (defendant not in lineup)

Non-ID (defendant in lineup)

Non-ID (defendant not in lineup)

$67.72(3.84)$

Note. Means under the eyewitness descriptor inconsistencies heading that do not share the same subscript differ at $p<.001$ in Tukey's HSD post hoc comparisons. 


\section{Discussion}

Often eyewitnesses provide inconsistent reports and have to view multiple lineups before they are able to identify the defendant in court. The purpose of the present investigation was to determine how mock jurors would view errors in eyewitness evidence, even if they were followed by correct eyewitness testimony. Therefore, the present study examined the effects of inconsistencies in the recall of criminal descriptors and eyewitness IDs on mock jurors' decisions. In addition to the previous juror decisionmaking research, the Story Model was used as a foundation to aid in predicting how mock jurors would process and manage the experimental manipulations. The findings of the present study and their relationship to the Story Model are discussed.

\section{Eyewitness Descriptor Inconsistencies}

As hypothesized, mock jurors rated the defendant as more guilty, the eyewitness' description of the criminal as more reliable, and eyewitness as higher overall (i.e., reliability, credibility, accuracy) when the eyewitness' description of the criminal contained 2 or 4 descriptor inconsistencies compared to when it contained 8 descriptor inconsistencies. These findings are congruent with previous literature reporting that eyewitness inconsistencies influence mock jurors' verdict decisions (Berman et al., 1995; Berman \& Cutler, 1996; Brewer \& Hupfeld, 2004) and eyewitness ratings (Berman et al., 1995; Berman \& Cutler, 1996; Brewer \& Hupfeld, 2004; Semmler \& Brewer, 2002). Specifically, these findings provide evidence that when it is brought to jurors' attention that the eyewitness' initial description of the criminal to the police is inconsistent with the appearance of the defendant in court, mock jurors are less likely to render guilty verdicts and less likely to provide favourable ratings to the eyewitness. However, guilty verdicts 
were only significantly less frequent when the eyewitness' description contained a large number of descriptor inconsistencies. Mock jurors' eyewitness and verdict ratings were similar regardless if the eyewitness' description contained 2 or 4 inconsistencies. Perhaps mock jurors were able to rationalize the incidence of 2 or 4 inconsistencies, especially since half of those inconsistencies were non-permanent details. For example, if the eyewitness' description contained 4 descriptor inconsistencies, mock jurors could reason that the defendant may have changed two aspects of his appearance and that it was not unreasonable for someone to incorrectly report 2 descriptor items. However, when the eyewitness' description contained 8 descriptor inconsistencies it was much more difficult for jurors to reason that the defendant had made four changes to his appearance and the eyewitness just "happened" to mistakenly report the other four (permanent) details.

The influence of eyewitness descriptor inconsistencies on mock jurors' ratings of the reliability of the eyewitness' ID decisions was mixed. Although in the expected direction, there were no significant effects of eyewitness descriptor inconsistencies on mock jurors' ratings of the reliability of the eyewitness' first or second photo lineup ID decisions. Therefore, mock jurors perceived the reliability of the eyewitness' lineup ID decisions as similar, regardless of how inconsistent the eyewitness' description of the criminal was with the appearance of the defendant in court. This finding is incongruent with research revealing that potential jurors believe that description accuracy and ID accuracy are related (Lindsay, 1994).

Mock jurors did, however, perceive the eyewitness' ID of the defendant in court as significantly more reliable when the eyewitness' description of the criminal contained 2 
or 4 descriptor inconsistencies compared to when it contained 8 descriptor inconsistencies. This is particularly interesting considering that the second lineup ID decision (positive ID of the suspect who is the defendant) and the ID of the defendant in court are essentially the same decisions. These conflicting findings beg the question, why would eyewitness' descriptor inconsistencies only influence mock jurors' perceptions of the reliability of an ID decision when it is made in court? In the trial transcript used, the eyewitness first provided a description of the criminal and it was days after that description that the eyewitness provided a first and second photo lineup ID decision. Perhaps due to the time difference between the tasks, mock jurors did not perceive the lineup IDs as related to the eyewitness' descriptor inconsistencies.

However, in court it was revealed that the eyewitness' original description of the criminal was inconsistent with the appearance of the defendant. During this trial, the eyewitness also made a positive ID of the defendant as the criminal. Mock jurors may have only associated the eyewitness descriptor inconsistencies with the ID of the defendant in court because the description of the man now identified also was inconsistent with the eyewitness' original description of the criminal.

The influence of eyewitness descriptor inconsistencies on mock jurors' judgments was generally congruent with the Story Model. Although mock jurors may conduct one or more stories when encountering a trial, jurors must select the one story which is most coherent (Hastie \& Pennington, 2000; Pennington \& Hastie, 1986, 1988, 1992). All mock jurors in the present study were presented with inconsistencies in the eyewitness' description of the criminal that needed to be reconciled in order to construct a coherent story. However, as the number of eyewitness descriptor inconsistencies increased it 
would become increasingly difficult for mock jurors to construct a coherent story, particularly with respect to the evidence presented by the prosecution compared to the defence. Using this line of reasoning, it was hypothesized that as evidence presented by the prosecution increased in inconsistency mock jurors would perceive the prosecution's evidence as weaker than the defence, resulting in lower guilt ratings and lower perceptions of the eyewitness This hypothesis was supported in the present study such that mock jurors rated the defendant as less guilty and the eyewitness less reliable on a number of dimensions when the eyewitness made 8 descriptor inconsistencies versus 2 or 4 descriptor inconsistencies.

\section{Eyewitness Identification Inconsistencies}

As hypothesized, eyewitness ID had a significant effect on mock jurors' verdicts, and mock jurors' ratings of the reliability of the first photo lineup ID, second photo lineup ID, and the eyewitness overall (i.e., reliability, credibility, and accuracy). However, due to the large number of post hoc comparisons a large Bonferroni correction $(p<.003)$ was made and the individual comparisons for the differences between ID types only remained significant for mock jurors' ratings of the reliability of the first photo lineup ID decision. The remaining follow-up analyses were primarily non-significant due to the stringent Bonferroni correction rather than a non effect of eyewitness ID.

Therefore, the individual comparisons for the differences between ID levels on mock jurors' ratings of the guilt of the defendant, the reliability of the second photo lineup ID, and the eyewitness overall also are interpreted and discussed.

Overall, the means were in the hypothesized direction such that mock jurors rated the defendant as more guilty, the eyewitness first photo lineup ID decision as more 
reliable, and the eyewitness was rated more positively overall when the eyewitness made an accurate ID (i.e., positive ID of the suspect who is the defendant, non-ID where the defendant is not in the lineup) and lower when the eyewitness made an error in ID (i.e., positive ID of the suspect who is different than the defendant, foil ID where the defendant is in/not in the lineup, non-ID where the defendant is in the lineup). These results are consistent with previous findings revealing that mock jurors use eyewitness ID evidence when making verdict decisions (Leippe, 1985; Lindsay et al., 1986; McAllister \& Bregman, 1986, 1989; Pozzulo et al., 2006) and assessing the reliability of the eyewitness making the ID (Pozzulo et al., 2006).

These findings are of further importance because they unify previous research suggesting that mock jurors underutilize non-IDs (McAllister \& Bregman, 1986; Pozzulo et al., 2006; Wells \& Lindsay, 1980) or in some cases underutilize positive IDs (Leippe, 1985; McAllister \& Bregman, 1989). There was virtually no difference in mock jurors' judgments when the eyewitness made an initial positive ID of the suspect who is the defendant and a non-ID where the defendant is not in the lineup. It seems that mock jurors are willing to perceive a non-ID as accurate as a positive ID, but this will only occur when it is certain that the defendant was not in the lineup and thus, rejected by the eyewitness.

Although there was little difference in mock jurors' judgments when the eyewitness made a positive ID of the suspect who is the defendant and a non-ID where the defendant is not in the lineup, there remains some evidence supporting Wells and Lindsay's (1980) contention that a positive ID is given more credence than a non-ID. There was no significant difference in mock jurors' ratings of the reliability of the 
eyewitness' first lineup ID when the eyewitness made a positive ID of the suspect who is the defendant, a positive ID of the suspect who is different than the defendant, and a nonID of the suspect where the defendant is not in the lineup. Accordingly, mock jurors perceived a positive ID as equally accurate regardless if the eyewitness chose the correct or incorrect suspect. Also, a positive ID of the suspect who is different than the defendant was perceived as more reliable than a non-ID of the suspect where the defendant is in the lineup. Although both of these ID decisions are essentially errors, it seems that choosing the wrong suspect is much more forgivable than missing the suspect in the lineup. Therefore a positive ID is perceived as reliable regardless if the decision is correct, but a non-ID is only perceived as reliable if it is clearly correct. These results also were found for mock jurors' mean ratings of the eyewitness' second photo lineup ID and the eyewitness overall.

In the trial transcript used for the present study, the defence revealed that the eyewitness also had viewed a second photo lineup, making a positive ID of the suspect who is the defendant. This occurred in all trial transcripts except when the eyewitness had originally made a positive ID of the suspect who is the defendant. Consistent with the hypothesis, mock jurors rated the eyewitness' second photo lineup ID as more reliable when the eyewitness had initially made an accurate ID (i.e., non-ID where the defendant is not in the lineup) than an error in ID (i.e., positive ID of the suspect who is different than the defendant, foil ID where the defendant is in/not in the lineup, non-ID where the defendant is in the lineup). The earlier review of the eyewitness ID literature revealed that introducing inconsistent IDs between eyewitnesses (i.e., one eyewitness makes a positive ID and one eyewitness makes a non-ID) substantially reduces mock jurors' guilt 
verdicts when compared to two positive IDs (Leippe, 1985; Lindsay et al., 1986;

McAllister \& Bregman, 1986). The findings in the present study support this body of literature such that mock jurors rated the second lineup ID decision as less reliable when it was preceded by an inconsistent ID decision. The present findings also extend this body of literature because they illustrate that it is not necessarily the actual ID decision that must be the same but the implication of the ID decision. For example, two positive IDs are generally consistent ID decisions. However, in the present study a positive ID of the suspect who is different than the defendant followed by a positive ID of the suspect who is the defendant represented inconsistent ID decisions because the eyewitness chose two different suspects. In contrast, a non-ID where the defendant is not in the lineup followed by a positive ID of the suspect who is the defendant represented two consistent ID decisions. The fact that mock jurors perceived the eyewitness' second lineup ID decision (i.e., positive ID of the suspect who is the defendant) as more reliable when preceded by a non-ID where the defendant was not in the lineup than a positive ID of the suspect who is different than the defendant illustrates that mock jurors recognize the implication and meaning of inconsistent ID decisions.

Contrary to the hypotheses, eyewitness ID did not influence mock jurors' perceptions of the reliability of the eyewitness' overall description of the criminal or ID of the defendant in court. Mock jurors perceived the reliability of the eyewitness' description of the criminal as virtually the same regardless of whether the eyewitness had made an erroneous or accurate ID decision. This finding is inconsistent with research revealing that mock jurors believe there is a positive relationship between ID accuracy and description accuracy (Lindsay, 1994). In contrast, the present findings actually 
support the eyewitness literature revealing that there is little or no relationship between these two different tasks (Goldstein et al., 1979; Meissner et al., 2007; Pigott et al., 1990; Pigott \& Brigham, 1985; Sporer, 1989).

There was no significant effect of eyewitness ID on mock jurors' ratings of the reliability of the eyewitness' $\mathrm{ID}$ of the defendant in court. Although ratings were highest when the eyewitness made an accurate ID (i.e., positive ID of the suspect who is the defendant, non-ID where the defendant is not in the lineup) and lower when the eyewitness made an ID error (i.e., positive ID of the suspect who is different than the defendant, foil ID where the defendant is in/not in the lineup, non-ID where the defendant is in the lineup), the mean ratings did not differ to the extent that they did for mock jurors' ratings of the first or second photo lineup IDs. Therefore, mock jurors perceived little difference in the reliability of the eyewitness' ID of the defendant in court, regardless of the eyewitness' initial ID decision.

It is surprising that eyewitness ID influenced mock jurors' perceptions of the reliability of the second photo lineup ID, but not the court ID, given that these IDs involved essentially the same decision (a positive ID of the defendant). Perhaps mock jurors suspected that the introduction of a second photo lineup was evidence that both lineup ID decisions were conducted improperly and contaminated by investigators. Mock jurors also may have assumed that the first photo lineup aided the eyewitness' second lineup ID decision. Either speculation would result in mock jurors perceiving the second photo lineup ID as related to the first. In contrast, because the eyewitness' ID of the defendant in court was simply a regurgitation of the second lineup ID, perhaps mock 
jurors did not perceive this decision as directly related to the eyewitness' first photo lineup ID, but rather a matter of procedure.

The present findings regarding the effect of eyewitness ID on mock jurors' judgments were in accordance with the Story Model, specifically with respect to the story classification stage. It was proposed that trial transcripts in which the eyewitness made an error in ID would cause jurors to be uncertain of the identity of the defendant, and thus find an insufficient match between the story constructed and a guilty verdict for the attempted murder charge. Consistent with this line of reasoning, mock jurors provided higher guilt ratings, higher ratings of the eyewitness' lineup ID decisions, and higher ratings of the eyewitness overall when the eyewitness made an accurate ID compared to an error in ID. Although, the effect of eyewitness ID only had a significant effect on mock jurors' ratings of the reliability of the eyewitness' first lineup ID decision, it is likely that jurors used this evidence in their verdict decisions. The mean differences in verdict ratings and other mock juror judgments as a function of eyewitness ID suggest that this was the case.

\section{Limitations and Future Research}

There were some limitations in the present study that should be considered. The ecological validity of juror research has often been debated, particularly with regards to the sample used, the absence of jury deliberations, and the methods of presentation (Diamond, 1997). The limitations of each area specific to the present study are discussed.

The participants in the present study, as in most juror research, were university undergraduate students. Although all university students were at least 18-years-old and 
thus jury eligible in Ontario, Diamond (1997) explains that several studies have demonstrated that there is reason to be skeptical of university students as representative of actual jurors. The researcher further suggests that the use of university participants and the general adult population is problematic because it is unknown how their responses to experimental manipulations may differ. However, using university students as mock jurors is perhaps more ecologically valid than one would intuitively believe. Bornstein (1999) reviewed a series of juror decision-making studies directly comparing university students and a non-student sample. Bornstein reported that of 26 studies, only 5 studies revealed a significant main effect of sample type on verdict decisions. The literature that revealed differences between students and other community members generally showed that students are more likely to find the defendant not guilty (Bornstein, 1999).

The leniency of student mock jurors could have potentially transpired in the present study's examination of eyewitness descriptor inconsistencies and ID. Specifically, if student jurors are more likely to find the defendant not guilty in general, this tendency might have been heightened when student jurors were exposed to information discrediting the prosecution's eyewitness. Therefore, it is questionable if the present study would have found the same effects if a community sample was used. Although Bornstein's (1999) review suggests that this is unlikely, replication with a community sample would provide insight regarding the ecological validity of the present study and add to the body of knowledge of how subsets of mock jurors differ as a function of eyewitness evidence. 
The ecological validity of the present study also is questionable due to the absence of deliberations among the jurors. The courts assume that the deliberation process improves jurors' memories through memory pooling and error correction, and thus verdict decisions are based on accuracy (Pritchard \& Keenan, 2002). The absence of juror deliberations in the present study could have been particularly problematic given the complexity of the experimental manipulations. For example, for the eyewitness ID manipulation where the eyewitness made a non-ID where the defendant was in the lineup, it was pertinent that mock jurors could understand and recall that the eyewitness first examined a photo lineup and did not identify anyone even though the defendant was in the lineup, and that it was not until viewing a second lineup that the eyewitness was able to identify the suspect who also was the defendant in the trial at hand. With such complex manipulations it is possible that mock jurors were not fully cognizant of the experimental manipulations, as evident in the manipulation check. Given the complexity of the trial used in the present study, mock jurors' verdicts may have been modified by the deliberation process.

On the other hand, there is some reason to assume that the outcomes of the present study would have been similar if the deliberation process was implemented. Leippe (1985) examined the influence of eyewitness ID and timing of measurement (prevs. post- deliberation) and found no main effect for timing of measurement and no interaction with eyewitness ID. In a more recent study, Pritchard and Keenan (2002) investigated jurors' memories and verdict decisions pre- and post- deliberation. The researchers revealed that deliberation only slightly enhanced jurors' memories, and jurors who changed their verdicts post-deliberation did not necessarily have poor memory 
accuracy but lower confidence in their memories. There is perhaps little concern that implementing the deliberation process would have enhanced the accuracy with which mock jurors rendered their verdicts, and thus result in findings different from the present study.

Juror decision-making research has introduced mock trials through various mediums (i.e., trial transcripts, video trials, audio trials, and live performances). However, Diamond (1997) asserts that trials are complex and lengthy procedures that cannot be fully represented through simulation. Diamond reports that various studies have revealed that experimental effect sizes may be artificially inflated when they occur in a trial simulation. The mock trial in the present study focused on descriptive and ID evidence presented by one key eyewitness. In order to efficiently study the relevant manipulations, mock jurors were not exposed to additional evidence (i.e., physical, DNA, alibi witnesses) that might be presented in an actual trial, providing jurors with a multitude of pertinent and extraneous information to make their decisions. For this reason, the effect of eyewitness descriptor inconsistencies and ID may have been exacerbated relative to its influence in an actual trial. Had there been no effect of the experimental manipulations, given the potentially heightened effect size, it would provide reason to suspect that the manipulations would not influence jurors' decisions in an actual trial (Diamond, 1997). Therefore, the findings in the present study, at the very least, illustrate that it is not unlikely that eyewitness descriptor inconsistencies and ID would influence juror decision-making in an actual trial.

A final limitation is with regards to the complexity of the experimental manipulations. The fact that few participants responded to the manipulation check with 
near or perfect accuracy indicates that mock jurors may not have fully understood the experimental manipulations. Future studies using similar manipulations could rectify this problem by implementing a pilot study to ensure mock jurors are cognizant of the experimental manipulations, and altering their presentation accordingly. On a positive note, mock jurors in the present study were permitted to refer to the trial transcript while completing the decision-making questionnaires. It was only during the manipulation check that mock jurors were not able to refer to the transcript. Therefore, the frequency of incorrect responses in the manipulation check may not reflect mock jurors' understanding, but simply their memory of the manipulations.

\section{Conclusion}

The present study examined how mock jurors' judgments are influenced when they are informed that that an eyewitness' initial description of the criminal and ID decisions are inconsistent with the information presented in court. Previous research has examined eyewitness description inconsistencies on mock jurors' decisions. The present study revealed findings supportive of the literature but also added to this body of research by examining eyewitness descriptor inconsistencies coupled with eyewitness ID evidence.

In actual trials, jurors are often unaware that eyewitnesses may have made multiple inconsistent ID decisions before being able to identify the defendant in court. The present study is the first investigation to examine how multiple inconsistent ID decisions will influence mock jurors' judgments. The results of the present study illustrate that presenting this evidence could potentially reduce guilty verdicts and further, prevent the incidence of wrongful convictions. In the decision to acquit Thomas 
Sophonow ( $R v$. Sophonow, 1986) after he had been wrongfully tried three times for the murder of Barbara Stoppel, it was stated that there had been several issues regarding the eyewitness evidence. Of particular relevance, it was revealed that the key identifying eyewitness, John Doerksen, was initially unable to identify Sophonow in a lineup. It was not until several days later that Doerksen was arrested for unrelated charges, brought to the same building as Sophonow, and shown Sophonow as the man accused of murdering Stoppel, that he was able to identify Sophonow as the criminal. According to the present findings, had this information been introduced to jurors when Doerksen first identified Sophonow in court, Sophonow may not have undergone multiple trials and the longstanding persecution he endured. 


\section{References}

Berman, G. L., \& Cutler, B. L. (1996). Effects of inconsistencies in eyewitness testimony on mock-juror decision making. Journal of Applied Psychology, 81, 170-177.

Berman, G. L., Narby, D. J., \& Cutler, B. L. (1995). Effects of inconsistent eyewitness statements on mock-jurors' evaluations of the eyewitness, perceptions of defendant culpability and verdicts. Law \& Human Behavior, 19, 79-88.

Bornstein, B. H. (1999). The ecological validity of jury simulations: Is the jury still out? Law \& Human Behavior, 23, 75-91.

Boyce, M., Beaudry, J., \& Lindsay, R. C. L. (2007). Belief of eyewitness identification evidence. In R. C. L. Lindsay, D. F. Ross, D. J. Read., \& M. P. Toglia (Eds.), The handbook of eyewitness of psychology: Vol. 2. Memory for people (pp. 501-525). Mahwah, NJ: Lawrence Erlbaum Associates Publishers.

Brewer, N., \& Burke, A. (2002). Effects of testimonial inconsistencies and eyewitness confidence on mock-juror judgments. Law \& Human Behavior, 26, 353-364.

Brewer, N., \& Hupfeld, R. M. (2004). Effects of testimonial inconsistencies and witness group identity on mock-juror judgments. Journal of Applied Social Psychology, $34,493-513$.

Brewer, N., Potter, R., Fisher, R. P., Bond, N., \& Luszcz, M. A. (1999). Beliefs and data on the relationship between consistency and accuracy of eyewitness testimony. Applied Cognitive Psychology, 13, 297-313.

Brown, C., \& Lloyd-Jones, T.J. (2005). Verbal facilitation of face recognition. Memory \& Cognition, 33, 1442-1456. 
Brown, C., \& Lloyd-Jones, T. J. (2006). Beneficial effects of verbalization and visual distinctiveness on remembering and knowing faces. Memory \& Cognition, 34, 277-286.

Cavoukian, A. (1980). The influence of eyewitness identification evidence. Unpublished doctoral dissertation, University of Toronto.

Clark, S. E., Howell, R. T., \& Davey, S. L. (2008). Regularities in eyewitness identification. Law \& Human Behavior, 32, 187-218.

Clark, S. E., \& Wells, G. L. (2008). On the diagnosticity of multiple-witness identifications. Law \& Human Behavior, 32, 406-422.

Criminal Code, R.S.C. 1985, c.46, s.239(1)

Culhane, S. E., \& Hosch, H. M. (2004). An alibi witness' influence on mock jurors' verdicts. Journal of Applied Social Psychology, 34, 1604-1616.

Cutler, B. L., Penrod, S. D., \& Dexter, H. R. (1990). Juror sensitivity to eyewitness identification evidence. Law \& Human Behavior, 14, 185-191.

Cutler, B. L., Penrod, S. D., \& Martens, T. K. (1987). The reliability of eyewitness identification: The role of system and estimator variables. Law \& Human Behavior, 11, 233-258.

Cutler, B. L., Penrod, S. D., \& Stuve, T. E. (1988). Juror decision making in eyewitness identification cases. Law \& Human Behavior, 12, 41-55.

Diamond, S. S. (1997). Illuminations and shadows from jury simulations. Law \& Human Behavior, 21, 561-571.

Dodson, C. S., Johnson, M. K., \& Schooler, J. W. (1997). The verbal overshadowing effect: Why descriptions impair face recognition. Memory \& Cognition, 25, 129- 
Elliot, R., Farrington, B., \& Manheimer, H. (1988). Eyewitness credible and discredible. Journal of Applied Social Psychology, 18, 1411-1422.

Ellis, H. D., Shepherd, J. W., \& Davies, G. M. (1980). The deterioration of verbal descriptions of faces over different delay intervals. Journal of Police Science and Administration, 8, 101-106.

Ellsworth, P. C., \& Mauro, R. (1998). Psychology and law. In D. T. Gilbert, S. T. Fiske, \& G. Lindzey (Eds.), The handbook of social psychology: Vol. 2 ( $4^{\text {th }} \mathrm{ed}$.) New York: McGraw-Hill. Pp. 684-732.

Fahsing, I. A., Ask, K., \& Granhag, P. A. (2004). The man behind the mask: Accuracy and predictors of eyewitness offender descriptions. Journal of Applied Psychology, 89(4), 722-729.

Fisher, R. P., \& Cutler, B. L. (1995). The relation between consistency and accuracy of eyewitness testimony. In G. M. Davies, S. Lloyd-Bostock, M. McMurran, \& C. Wilson (Eds.), Psychology, law and criminal justice: International developments in research and practice (pp. 21-28). Berlin: DeGruyter.

Flin, R. H., \& Shepherd, J. W. (1986). Tall stories: Eyewitnesses' ability to estimate height and weight characteristics. Human Learning, 5, 29-38.

Garcia, L. T., \& Griffitt, W. (1978). Impact of testimonial evidence as a function of witness characteristics. Bulletin of the Psychonomic Society, 11, 37-40.

Goldstein, A. G., Johnson, K. S., \& Chance, J. E. (1979). Does fluency of face description imply superior face recognition? Bulletin of the Psychonomic Society, 13, 15-18. 
Hastie, R., \& Pennington, N. (2000). Explanation-based decision making. In T. Connolly et al. (Eds.), Judgment and decision making: An interdisciplinary reader $\left(2^{\text {nd }}\right.$ ed., pp. 212-228). New York: Cambridge University Press.

Hatvany, N., \& Strack, F. (1980). The impact of a discredited key witness. Journal of Applied Social Psychology, 10, 490-509.

Hinz, T., \& Pezdek, K. (2001). The effect of exposure to multiple lineups on face identification accuracy. Law \& Human Behavior, 25, 185-197.

Itoh, Y. (2005). The facilitating effect of verbalization on the recognition memory of incidentally learned faces. Applied Cognitive Psychology, 19, 421-433.

Kennedy, T. D., \& Haygood, R. C. (1992). The discrediting effect in eyewitness testimony. Journal of Applied Social Psychology, 22, 70-82.

Kuehn, L. L. (1974). Looking down a gun barrel: Person perception and violent crime. Perceptual and Motor Skills, 39, 1159-1164.

Leippe, M. R. (1985). The influence of eyewitness nonidentifications on mock-jurors' judgments of a court case. Journal of Applied Social Psychology, 15, 656-672.

Leippe, M. R., \& Romanczyk, A. (1989). Reactions to child (versus adult) eyewitnesses: The influence of jurors' preconceptions and witness behavior. Law \& Human Behavior, 13, 103-132.

Levi, A. M. (1998). Are defendants guilty if they were chosen in a lineup? Law \& Human Behavior, 22, 389-407.

Lindsay, R. C. L. (1994). Expectations of eyewitness performance: Jurors' verdicts do 
not follow from their beliefs. In D. F. Ross, J. D. Read, \& M. P. Toglia (Eds.), Adult eyewitness testimony: Current trends and developments (pp. 362-384). New York, NY: Cambridge University Press.

Lindsay, R. C. L., Lim, R., Marando, L., \& Cully, D. (1986). Mock-juror evaluations of eyewitness testimony: A test of metamemory hypotheses. Journal of Applied Social Psychology, 16, 447-459.

Lindsay, R. C. L., Martin, R., \& Webber, L. (1994). Default values in eyewitness descriptions. Law \& Human Behavior, 18, 524-541.

Lindsay, R. C. L., \& Wells, G. L. (1980). What price justice? Exploring the relationship of lineup fairness to identification accuracy. Law \& Human Behavior, 4, 303-314.

Loftus, E. (1974). Reconstructing memory: The incredible eyewitness. Psychology Today, 8, 116-119.

Lopes, L. (1993). Two conceptions of the juror. In R. Hastie (Ed.), Inside the juror: The psychology of juror decision making (pp. 255-262). New York, NY: Cambridge University Press.

Mauldin, M. A., \& Laughery, K. R. (1981). Composite production effects on subsequent facial recognition. Journal of Applied Psychology, 66, 351-357.

McAllister, H. A., \& Bregman, N. J. (1986) Juror underutilization of eyewitness nonidentifications: Theoretical and practical implications. Journal of Applied Psychology, 71, 168-170.

McAllister, H. A., \& Bregman, N. J. (1989). Juror underutilization of eyewitness nonidentifications: A test of the disconfirmed expectancy explanation. Journal of Applied Social Psychology, 19, 20-29. 
McCullough, G. W. (2007). Function of text structure in jurors' comprehension and decision making. Psychological Reports, 101, 723-730.

Meissner, C. A., \& Brigham, J. C. (2001). A meta-analysis of the verbal overshadowing effect in face identification. Applied Cognitive Psychology, 15, 603-616.

Meissner, C. A., Brigham, J. C., \& Kelley, C. M. (2001). The influence of retrieval processes in verbal overshadowing. Memory \& Cognition, 29, 176-186.

Meissner, C. A., Sporer, S. L., \& Schooler, J. W. (2007). Person descriptions as eyewitness evidence. In R. C. L. Lindsay, D. Ross, J. Read, \& M. Toglia (Eds.), Handbook of eyewitness psychology: Memory for people (pp. 3-34). Hillsdale, NJ: Lawrence Erlbaum Associates, Inc.

Meissner, C. A., Sporer, S. L., \& Susa, K. J. (2008). A theoretical review and metaanalysis of the description-identification relationship in memory for faces.

European Journal of Cognitive Psychology, 20, 414-455.

Pennington, N., \& Hastie, R. (1986). Evidence evaluation in complex decision making. Journal of Personality \& Social Psychology, 51, 242-258.

Pennington, N., \& Hastie, R. (1988). Explanation-based decision making: Effects of memory structure on judgment. Journal of Experimental Psychology: Learning Memory, \& Cognition, 14, 521-533.

Pennington, N., \& Hastie, R. (1992) Explaining the evidence: Tests of the story model for juror decision making. Journal of Personality \& Social Psychology, 62, 189-206.

Pezdek, K., \& Blandon-Gitlin, I. (2005). When is an intervening line-up most likely to affect eyewitness identification accuracy? Legal \& Criminological Psychology, 10, 247-263. 
Pigott, M. A., \& Brigham, J. C. (1985). Relationship between accuracy of prior description and facial recognition. Journal of Applied Psychology, 70, 547-555.

Pigott, M. A., Brigham, J. C., \& Bothwell, R. K. (1990). A field study on the relationship between quality of eyewitnesses' descriptions and identification accuracy. Journal of Police Science and Administration, 17, 84-88.

Pozzulo, J. D., Lemieux, J. M. T., Wells, E., \& McCuaig, H. J. (2006). The influence of eyewitness identification decisions and age of witness on jurors' verdicts and perceptions of reliability. Psychology, Crime \& Law, 12, 641-652.

Pozzulo, J. D., \& Warren, K. L. (2003). Descriptions and identifications of strangers by youth and adult eyewitnesses. Journal of Applied Psychology, 88, 315-323.

Pritchard, M. E., \& Keenan, J. M. (2002). Does jury deliberation really improve jurors' memories? Applied Cognitive Psychology, 16, 589-601.

R. v. Sophonow (No.2), 1986 CanLII 104 (MB C.A.).

Read, J. D. (1979). Rehearsal and recognition of human faces. American Journal of Psychology, 92, 71-85.

Sanders, G. S., \& Warnick, D. H. (1982). Evaluating identification evidence from multiple eyewitnesses. Journal of Applied Social Psychology, 12, 182-192.

Saunders, D. M., Vidmar, N., \& Hewitt, E. C (1983). Eyewitness testimony and the discrediting effect. In S. M. A. Lloyd-Bostock \& B. R. Clifford (Eds.), Evaluating eyewitness evidence. (pp. 57-78). London: John Wiley.

Schooler, J. W., \& Engstler-Schooler, T. Y. (1990). Verbal overshadowing of visual memories: Some things are better left unsaid. Cognitive Psychology, 22, 36-71. 
Semmler, C., \& Brewer, N. (2002). Effects of mood and emotion on juror processing and judgments. Behavioral Sciences \& the Law, 20, 423-436.

Sigler, J. N., \& Couch, J. V. (2002). Eyewitness testimony and the jury verdict. North American Journal of Psychology, 4, 143-148.

Sporer, S. L. (1989) Verbal and visual processes in person identification. In H. Wegener, F. Loesel, \& J. Haisch (Eds.), Criminal behavior and the justice system: Psychological perspectives, (pp. 303-324). New York: Springer.

Sporer, S. L. (1992). Post-dicting eyewitness accuracy: Confidence, decision-times and person descriptions of choosers and non-choosers. European Journal of Social Psychology, 22, 157-180.

Sporer, S. L. (1996). Psychological aspects of person descriptions. In S. Sporer, R. Malpass, \& G. Koehnken (Eds.), Psychological issues in eyewitness identification (pp. 53-86). Mahwah, NJ: Erlbaum.

Sporer, S. L. (2007). Person descriptions as retrieval cues: Do they really help? Psychology, Crime, \& Law, 13, 591-609.

Tabachnick, B. G., \& Fidell, L. S. (2007). Experimental Designs Using ANOVA. Belmont, CA: Duxbury.

Tenney, E. R., MacCoun, R. J., Spellman, B. A., \& Hastie, R. (2007). Calibration trumps confidence as a basis for witness credibility. Psychological Science, 18, 46-50.

Tetterton, V. S., \& Warren, A. R. (2005). Using witness confidence can impair the ability to detect deception. Criminal Justice \& Behavior, 32, 433-451.

van Koppen, P. J., \& Lochun, S. K. (1997). Portraying perpetrators: The validity of offender descriptions by witnesses. Law \& Human Behavior, 21, 661-685. 
Weinberg, H. I., \& Baron, R. S. (1982). The discredible witness. Personality \& Social Psychology Bulletin, 8(1), 60-67.

Wells, G. L. (1985). Verbal descriptions of faces from memory: Are they diagnostic of identification accuracy? Journal of Applied Psychology, 70, 619-626.

Wells, G. L. (1993). What do we know about eyewitness identification? American Psychologist, 48(5), 553-571.

Wells, G. L., \& Lindsay, R. C. L. (1980). On estimating the diagnosticity of eyewitness nonidentifications. Psychological Bulletin, 88, 776-784.

Wells, G. L., Lindsay, R. C. L., \& Ferguson, T. J. (1981). The tractability of eyewitness confidence and its implications for triers of fact. Journal of Applied Psychology, 66, 688-696.

Wells, G. L., \& Luus, C. A. E. (1990). The diagnosticity of a lineup should not be confused with the diagnostic value of non-lineup evidence. Journal of Applied Psychology, 75, 511-516

Wells, G. L., \& Olson, E. A. (2002). Eyewitness identification: Information gain from incriminating and exonerating behaviors. Journal of Experimental Psychology: Applied, 8, 155-167.

Wells., G. L., \& Turtle, J. W. (1986). Eyewitness identification: The importance of lineup models. Psychological Bulletin, 99, 320-329.

Whitley, B. E. (2001). The effects of discredited eyewitness testimony: A meta-analysis. Journal of Social Psychology, 127, 209-214.

Yarmey, A. D. (1993). Adult age and gender differences in eyewitness recall in field settings. Journal of Applied Social Psychology, 23, 1921-1932. 
Yarmey, A. D. (2004). Eyewitness recall and photoidentification: A field experiment. Psychology, Crime, \& Law, 10, 53-68.

Yarmey, A. D., Jacob, J., \& Porter, A. (2002). Person recall in field settings. Journal of Applied Social Psychology, 32, 2354-2367.

Yarmey, A. D., \& Yarmey, M. J. (1997). Eyewitness recall and duration estimates in field settings. Journal of Applied Social Psychology, 24, 330-344.

Yuille, J. C., \& Cutshall, J. L. (1986). A case study of eyewitness memory of a crime. Journal of Applied Psychology, 71, 291-301. 


\section{Appendix A}

\section{Trial Transcript}

\section{Please read the following carefully}

This is a trial involving an attempted murder that occurred during a liquor store robbery. The section below consists of the eyewitness testimony of the cashier (the victim) working in the liquor store at the time of the robbery, and the defendant.

Judge: Mr. Sullivan has been charged with section 239(1) of the Criminal Code, Attempt to commit murder. The Crown has the burden of proving that charge beyond a reasonable doubt. It is your responsibility to listen to all the evidence, to decide the facts, and then to apply the law that I will give you at the end of the trial. The case will begin with opening statements from both the Crown and Defence attorneys. These statements are not evidence, yet summaries of what will be presented in the trial. Following these statements, the Crown and Defence will present and question two witnesses, who will subsequently be cross-examined. Please listen to the following arguments carefully. Following the testimonies, you will be asked to make a decision as to whether you find the defendant, Mr. Sullivan, guilty or not guilty of the charge.

\section{The Crown makes their opening statement.}

Crown: Mr. Joseph Sullivan is a man without a steady income. On December 12, 2007, Mr. Sullivan, looking for some quick cash, entered the LCBO in the Glendale Street Plaza with the intent to rob the establishment at any cost. Armed with a loaded gun, Mr. Sullivan threatened to shoot the cashier if she did not comply with his demands. He ordered the cashier to take him to the back room to remove the surveillance tape and turn off the cameras. He then had the cashier empty the cash register and put the money in a duffle bag he was carrying with him. When Mr. Sullivan became concerned by a group of people passing the store, the cashier grabbed her cell phone and dialed 911. However, when Mr. Sullivan became aware of this he became enraged and shot the victim in the chest. He took the money and fled the store, leaving the victim for dead. Mr. Sullivan attempted to murder an innocent person, due to his own rage during an act of greed for money. It is therefore, your duty, as representatives of our community, to seek justice finding Mr. Sullivan guilty of attempted murder.

\section{The Defence makes their opening statement.}

Defence: Mr. Sullivan did not commit attempted murder. Yes, it is true that Mr. Sullivan somewhat matches the description provided by the victim. However, the accusation that Mr. Sullivan attempted to murder the cashier of a liquor store during a robbery is completely and utterly false. I would like to propose a different theory to you today. A theory based on convenience. Mr. Sullivan was unemployed and happened to live in an apartment close to the strip mall when the crime occurred. He somewhat matched the description provided by the victim and, as a result, Mr. Sullivan was apprehended. I 
would like to call attention to the fact that Mr. Sullivan has no criminal record, and no past history of any violence. To assume that Mr. Sullivan committed this crime is preposterous. I trust that you will consider all of the information presented to you and find that my client is indeed not guilty.

\section{The 2 Descriptor Inconsistencies Condition}

\section{Correct Descriptors}

Age, weight, height, eye colour, nose, hair colour, hair length, ear piercing, Incorrect Descriptors

Permanent: Mole Non Permanent: Facial hair

The Crown calls their first witness, Diane Johnson (the victim), and she takes the stand.

Crown: Can you please state your full name for the Court?

Witness: My name is Diane Johnson.

Crown: Where do you work Miss Johnson?

Witness: I work at the LCBO in the Glendale Street Plaza.

Crown: Could you please tell us what happened on the night of December 12, 2007, at your place of employment?

Witness: Closing time was approaching so I was mopping the floors near the back end of the store. Suddenly, I noticed someone out of the corner of my eye and a hard object was driven into my back. Soon after, a deep voice said "Hold it right there! This is a robbery. If you do as I say, then you won't get hurt. Any sudden moves, I will shoot! Try to call for help and I will kill you. Got it?" I nodded and said "yes," under my breath.

Crown: Just to clarify, what was the object the man stuck into your back?

Witness: It was a gun.

Crown: Thank you, Miss Johnson. Please continue, what did the man do after threatening your life with a deadly weapon?

Witness: First, he asked me where the surveillance was. I told him it was in the back. $\mathrm{He}$ ordered me with his gun to go to the back with him, shut off the cameras, and give him the surveillance tape.

Crown: And what happened after the man obtained the surveillance video?

Witness: The man placed the video in his bag. Then he said, "Ok, now get to the cash register!" He walked beside me toward the cash register, still pointing the gun at me. $\mathrm{He}$ ordered me to open the till and place all of the cash in the bag. While emptying the till, he must have heard some people walking outside the plaza. "Wait here!" He said. "And don't move, or I'll shoot you." He crept toward the front of the store.

Crown: What did you do while the criminal went to the front of the store?

Witness: I had just finished placing all of the money in the bag when he told me not to move. I realized this was my chance. I grabbed my cell phone from my back pocket. I know it shouldn't have been there, but I was texting my friend near the end of my shift to ask her if she was picking me up from work. I quickly dialed 911.

Crown: Then what happened?

Witness: The man came back toward the counter before I knew it so my first instinct was to put my hand behind my back.

Crown: Did the man notice? 
Witness: Yes, he grabbed my arm and pulled me out from behind the counter and the phone fell to the floor. He saw that I dialed 911.

Crown: How did the criminal react when he saw that you had dialed 911 ?

Witness: He picked up the phone, quickly closed it, and started yelling at me furiously. "I told you not to call for help. Now you have done it, this is all your fault! I have no choice, I told you what would happen if you called for help!"

Crown: What did you do Miss Johnson?

Witness: I begged and pleaded. "No, please don't! Please!" I cried. He told me to shut up. The next thing I knew he fired the gun and I fell to the floor. He shot me in the chest. He grabbed the bag from the counter and fled the store.

Crown: After you were brought to the hospital and multiple surgeries were performed in attempt to save your life, did you ever speak to the police?

Witness: Yes, when I was well enough for visitors a police officer arrived and asked me to provide a description of the criminal.

Crown: What did you tell the officer?

Witness: I explained that the man was approximately 25-30 years of age, 170 to 180 pounds, and about 5' 10 , taller than me anyway. The man had blue eyes, a nose bump, and a mole on his left cheek. His hair was brown and shoulder length. He also had a goatee and a gold earring in his right ear.

Crown: Miss Johnson, in your initial description to the police you had reported that the criminal was between $25-30$ years of age, is that correct?

Witness: Yes, that is correct.

Crown: Mr. Sullivan is in fact 28-years-old. Miss Johnson, you initially stated that the criminal was between 170 and 180 pounds?

Witness: Yes, that is correct.

Crown: Well, Mr. Sullivan, the defendant sitting before the Court, is 176 pounds. Miss Johnson, how tall are you?

Witness: About 5',".

Crown: And you stated that the criminal must be around 5' 10 " because he was taller than you?

Witness: Yes.

Crown: Well Miss Johnson, the defendant who sits here today on trial is in fact 5'10," which is clearly taller than you. You also stated in your description of the criminal that he had blue eyes, is that correct?

Witness: Yes, I did.

Crown: Miss Johnson, looking at the defendant, Mr. Sullivan, sitting in this Courtroom can you please tell me the colour of his eyes?

Witness: They look to be blue from here.

Crown: Yes, that is correct. You also stated that the criminal had a nose bump, is that correct?

Witness: Yes, that is correct.

Crown: Does the defendant, Mr. Sullivan, have a nose bump?

Witness: Yes, he does.

Crown: Also, you stated earlier that you described the criminal as having brown hair? Would you say Mr. Sullivan's hair is brown?

Witness: Yes. 
Crown: Miss Johnson, earlier you mentioned that you had also reported to the police that the criminal had shoulder length hair. Would you say the defendant has shoulder length hair?

Witness: Yes I would.

Crown: Miss Johnson, in your report to the police you also stated that the criminal had a gold earring in his right ear, is that correct?

Witness: Yes.

Crown: Does the defendant have a gold earring in his right ear?

Witness: Yes.

Crown: Miss Johnson, is the man that you have just described present in this Courtroom today?

Witness: Yes, he is right over there. (The witness points to the defendant).

Crown: Would the Court please note that the witness has identified the defendant.

Thank you Miss Johnson. No further questions your Honour.

The Defence cross-examines the witness.

Defence: Miss Johnson, you mentioned that when the criminal first came into the store, he clearly stated that if you attempted to call for help, he would kill you?

Witness: Yes, that is correct.

Defence: Earlier you stated that you dialed 911 when he turned his back for a mere moment?

Witness: It was more than a moment.

Defence: Please just answer the question.

Witness: Yes, I called for help.

Defence: Were you trying to provoke the criminal?

Witness: Provoke?

Defence: Were you trying to test him Miss Johnson?

Witness: Test, I don't...

Crown: Objection, your Honour this is preposterous.

Judge: Sustained.

Defence: I withdraw my question your Honour. Miss Johnson, how long would you say that the robbery took place?

Witness: About 12 to 15 minutes.

Defence: So you would say that you had a decent amount of time to view the criminal?

Witness: Yes, I would say so.

Defence: And how long were you in the hospital before you provided the police officer with a description of the criminal?

Witness: Well I was sleeping most of the time before, I had undergone a severe gunshot wound and multiple surgeries, but my mom said I was there for about 14 hours prior to my questioning.

Defence: So what you are telling me is that you don't remember a lot of it?

Witness: Yes, I guess so.

Defence: Isn't it possible that during this time you forgot some of the details of the crime, including the description of the criminal?

Witness: No, I wouldn't say that. 
Defence: Miss Johnson, you testified that you initially reported to the police that the criminal had a mole on his left cheek?

Witness: Yes, I did.

Defence: Looking at Mr. Sullivan, the defendant on trial, do you see a mole on his left cheek?

Witness: No, I don't.

Defence: Clearly you were mistaken when you reported the criminal as having a mole on his left cheek?

Witness: I don't know.

Defence: Miss Johnson, in the description you gave to the police, you had stated that the criminal had a goatee.

Witness: Yes, that's correct.

Defence: Does the defendant have a goatee?

Witness: No.

Defence: So you admit that you were wrong when you stated the criminal had a goatee?

Witness: Well, I am just saying that he doesn't have a goatee now.

\section{The 4 Descriptor Inconsistencies Condition}

\section{Correct Descriptors}

Weight, height, eye colour, nose, hair colour, ear piercing

Incorrect Descriptors

Permanent: age, mole Non-Permanent: hair length, facial hair

The Crown calls their first witness, Diane Johnson, and she takes the stand.

Crown: Can you please state your full name for the Court?

Witness: My name is Diane Johnson.

Crown: Where do you work Miss Johnson?

Witness: I work at the LCBO in the Glendale Street Plaza.

Crown: Could you please tell us what happened on the night of December 12, 2007, at your place of employment?

Witness: Closing time was approaching so I was mopping the floors near the back end of the store. Suddenly, I noticed someone out of the corner of my eye and a hard object was driven into my back. Soon after, a deep voice said "Hold it right there! This is a robbery. If you do as I say, then you won't get hurt. Any sudden moves, I will shoot! Try to call for help and I will kill you. Got it?" I nodded and said "yes," under my breath. Crown: Just to clarify, what was the object the man stuck into your back? Witness: It was a gun.

Crown: Thank you, Miss Johnson. Please continue, what did the man do after threatening your life with a deadly weapon?

Witness: First, he asked me where the surveillance was. I told him it was in the back. He ordered me with his gun to go to the back with him, shut off the cameras, and give him the surveillance tape.

Crown: And what happened after the man obtained the surveillance video?

Witness: The man placed the video in his bag. Then he said, "Ok, now get to the cash register!" He walked beside me toward the cash register, still pointing the gun at me. He 
ordered me to open the till and place all of the cash in the bag. While emptying the till, he must have heard some people walking outside the plaza. "Wait here!" He said. "And don't move, or I'll shoot you." He crept toward the front of the store.

Crown: What did you do while the criminal went to the front of the store?

Witness: I had just finished placing all of the money in the bag when he told me not to move. I realized this was my chance. I grabbed my cell phone from my back pocket. I know it shouldn't have been there, but I was texting my friend near the end of my shift to ask her if she was picking me up from work. I quickly dialed 911.

Crown: Then what happened?

Witness: The man came back toward the counter before I knew it so my first instinct was to put my hand behind my back.

Crown: Did the man notice?

Witness: Yes, he grabbed my arm and pulled me out from behind the counter and the phone fell to the floor. He saw that I dialed 911.

Crown: How did the criminal react when he saw that you had dialed 911 ?

Witness: He picked up the phone, quickly closed it, and started yelling at me furiously. "I told you not to call for help. Now you have done it, this is all your fault! I have no choice, I told you what would happen if you called for help!"

Crown: What did you do Miss Johnson?

Witness: I begged and pleaded. "No, please don't! Please!" I cried. He told me to shut up. The next thing I knew he fired the gun and I fell to the floor. He shot me in the chest. He grabbed the bag from the counter and fled the store.

Crown: After you were brought to the hospital and multiple surgeries were performed in attempt to save your life, did you ever speak to the police?

Witness: Yes, when I was well enough for visitors a police officer arrived and asked me to provide a description of the criminal.

Crown: What did you tell the officer?

Witness: I explained that the man was approximately 25-30 years of age, 170 to 180 pounds, and about 5'10, taller than me anyway. The man had blue eyes, a nose bump, and a mole on his left cheek. His hair was brown and shoulder length. He also had a goatee and a gold earring in his right ear.

Crown: Miss Johnson, you initially stated that the criminal was between 170 and 180 pounds?

Witness: Yes, that is correct.

Crown: Well, Mr. Sullivan, the defendant sitting before the Court, is 176 pounds. Miss Johnson, how tall are you?

Witness: About 5'8".

Crown: And you stated that the criminal must be around 5'10" because he was taller than you?

Witness: Yes.

Crown: Well Miss Johnson, the defendant who sits here today on trial is in fact 5'10," which is clearly taller than you. You also stated in your description of the criminal that he had blue eyes, is that correct?

Witness: Yes, I did.

Crown: Miss Johnson, looking at the defendant, Mr. Sullivan, sitting in this Courtroom can you please tell me the colour of his eyes? 
Witness: They look to be blue from here.

Crown: Yes, that is correct. You also stated that the criminal had a nose bump, is that correct?

Witness: Yes, that is correct.

Crown: Does the defendant, Mr. Sullivan, have a nose bump?

Witness: Yes, he does.

Crown: Also, you stated earlier that you described the criminal as having brown hair?

Would you say Mr. Sullivan's hair is brown?

Witness: Yes.

Crown: Miss Johnson, in your report to the police you also stated that the criminal had a gold earring in his right ear, is that correct?

Witness: Yes.

Crown: Does the defendant have a gold earring in his right ear?

Witness: Yes.

Crown: Miss Johnson, is the man that you have just described present in this Courtroom today?

Witness: Yes, he is right over there. (The witness points to the defendant).

Crown: Would the Court please note that the witness has identified the defendant. Thank you Miss Johnson. No further questions your Honour.

The Defence cross-examines the witness.

Defence: Miss Johnson, you mentioned that when the criminal first came into the store, he clearly stated that if you attempted to call for help, he would kill you?

Witness: Yes, that is correct.

Defence: Earlier you stated that you dialed 911 when he turned his back for a mere moment?

Witness: It was more than a moment.

Defence: Please just answer the question.

Witness: Yes, I called for help.

Defence: Were you trying to provoke the criminal?

Witness: Provoke?

Defence: Were you trying to test him Miss Johnson?

Witness: Test, I don't...

Crown: Objection, your Honour this is preposterous.

Judge: Sustained.

Defence: I withdraw my question your Honour. Miss Johnson, how long would you say that the robbery took place?

Witness: About 12 to 15 minutes.

Defence: So you would say that you had a decent amount of time to view the criminal?

Witness: Yes, I would say so.

Defence: And how long were you in the hospital before you provided the police officer with a description of the criminal?

Witness: Well I was sleeping most of the time before, I had undergone a severe gunshot wound and multiple surgeries, but my mom said I was there for about 14 hours prior to my questioning. 
Defence: So what you are telling me is that you don't remember a lot of it?

Witness: Yes, I guess so.

Defence: Isn't it possible that during this time you forgot some of the details of the crime, including the description of the criminal?

Witness: No, I wouldn't say that.

Defence: Miss Johnson, in your initial description to the police you had reported that the criminal was between $25-30$ years of age, is that correct?

Witness: Yes, that is correct.

Defence: Do you know the actual age of Mr. Sullivan, the defendant?

Witness: Again, I would say between 25-30 years of age.

Defence: Mr. Sullivan is actually 35 -years-old. So you must have been incorrect when you reported the criminal as between 25-30 years of age?

Witness: I guess so.

Defence: Miss Johnson, you testified that you initially reported to the police that the criminal had a mole on his left cheek?

Witness: Yes, I did.

Defence: Looking at Mr. Sullivan, the defendant on trial, do you see a mole on his left cheek?

Witness: No, I don't.

Defence: Clearly you were mistaken when you reported the criminal as having a mole on his left cheek?

Witness: I don't know.

Defence: Miss Johnson, earlier you mentioned that you had also reported to the police that the criminal had shoulder length hair. Would you say the defendant has shoulder length hair?

Witness: Maybe he cut it.

Defence: I did not ask you if he cut his hair, I asked you how long his hair is.

Witness: It is very short, like a brush cut.

Defence: So you must have been mistaken when you stated that the criminal had shoulder length hair?

Witness: Um, I don't know.

Defence: Miss Johnson, in the description you gave to the police, you had stated that the criminal had a goatee.

Witness: Yes, that's correct.

Defence: Does the defendant have a goatee?

Witness: No.

Defence: So you admit that you were wrong when you stated the criminal had a goatee? Witness: Well, I am just saying that he doesn't have a goatee now. 


\section{The 8 Descriptor Inconsistencies Condition}

\section{Correct Descriptors}

weight, nose

Incorrect Descriptors

Permanent: age, height, eye colour, mole Non-Permanent: hair colour, hair length, facial hair, ear piercing

The Crown calls their first witness, Diane Johnson, and she takes the stand.

Crown: Can you please state your full name for the Court?

Witness: My name is Diane Johnson.

Crown: Where do you work Miss Johnson?

Witness: I work at the LCBO in the Glendale Street Plaza.

Crown: Could you please tell us what happened on the night of December 12, 2007, at your place of employment?

Witness: Closing time was approaching so I was mopping the floors near the back end of the store. Suddenly, I noticed someone out of the corner of my eye and a hard object was driven into my back. Soon after, a deep voice said "Hold it right there! This is a robbery. If you do as I say, then you won't get hurt. Any sudden moves, I will shoot! Try to call for help and I will kill you. Got it?" I nodded and said "yes," under my breath.

Crown: Just to clarify, what was the object the man stuck into your back?

Witness: It was a gun.

Crown: Thank you, Miss Johnson. Please continue, what did the man do after threatening your life with a deadly weapon?

Witness: First, he asked me where the surveillance was. I told him it was in the back. He ordered me with his gun to go to the back with him, shut off the cameras, and give him the surveillance tape.

Crown: And what happened after the man obtained the surveillance video?

Witness: The man placed the video in his bag. Then he said, "Ok, now get to the cash register!" He walked beside me toward the cash register, still pointing the gun at me. $\mathrm{He}$ ordered me to open the till and place all of the cash in the bag. While emptying the till, he must have heard some people walking outside the plaza. "Wait here!" He said. "And don't move, or I'll shoot you." He crept toward the front of the store.

Crown: What did you do while the criminal went to the front of the store?

Witness: I had just finished placing all of the money in the bag when he told me not to move. I realized this was my chance. I grabbed my cell phone from my back pocket. I know it shouldn't have been there, but I was texting my friend near the end of my shift to ask her if she was picking me up from work. I quickly dialed 911.

Crown: Then what happened?

Witness: The man came back toward the counter before I knew it so my first instinct was to put my hand behind my back.

Crown: Did the man notice?

Witness: Yes, he grabbed my arm and pulled me out from behind the counter and the phone fell to the floor. He saw that I dialed 911.

Crown: How did the criminal react when he saw that you had dialed 911 ? 
Witness: He picked up the phone, quickly closed it, and started yelling at me furiously. "I told you not to call for help. Now you have done it, this is all your fault! I have no choice, I told you what would happen if you called for help!"

Crown: What did you do Miss Johnson?

Witness: I begged and pleaded. "No, please don't! Please!" I cried. He told me to shut up. The next thing I knew he fired the gun and I fell to the floor. He shot me in the chest. He grabbed the bag from the counter and fled the store.

Crown: After you were brought to the hospital and multiple surgeries were performed in attempt to save your life, did you ever speak to the police?

Witness: Yes, when I was well enough for visitors a police officer arrived and asked me to provide a description of the criminal.

Crown: What did you tell the officer?

Witness: I explained that the man was approximately 25-30 years of age, 170 to 180 pounds, and about 5'10, taller than me anyway. The man had blue eyes, a nose bump, and a mole on his left cheek. His hair was brown and shoulder length. He also had a goatee and a gold earring in his right ear.

Crown: Miss Johnson, you initially stated that the criminal was between 170 and 180 pounds?

Witness: Yes, that is correct.

Crown: Well, Mr. Sullivan, the defendant sitting before the Court, is 176 pounds. You also stated that the criminal had a nose bump, is that correct?

Witness: Yes, that is correct.

Crown: Does the defendant, Mr. Sullivan, have a nose bump?

Witness: Yes, he does.

Crown: Miss Johnson, is the man that you have just described present in this Courtroom today?

Witness: Yes, he is right over there. (The witness points to the defendant).

Crown: Would the Court please note that the witness has identified the defendant. Thank you Miss Johnson. No further questions your Honour.

The Defence cross-examines the witness.

Defence: Miss Johnson, you mentioned that when the criminal first came into the store, he clearly stated that if you attempted to call for help, he would kill you?

Witness: Yes, that is correct.

Defence: Earlier you stated that you dialed 911 when he turned his back for a mere moment?

Witness: It was more than a moment.

Defence: Please just answer the question.

Witness: Yes, I called for help.

Defence: Were you trying to provoke the criminal?

Witness: Provoke?

Defence: Were you trying to test him Miss Johnson?

Witness: Test, I don't...

Crown: Objection, your Honour this is preposterous. Judge: Sustained. 
Defence: I withdraw my question your Honour. Miss Johnson, how long would you say that the robbery took place?

Witness: About 12 to 15 minutes.

Defence: So you would say that you had a decent amount of time to view the criminal?

Witness: Yes, I would say so.

Defence: And how long were you in the hospital before you provided the police officer with a description of the criminal?

Witness: Well I was sleeping most of the time before, I had undergone a severe gunshot wound and multiple surgeries, but my mom said I was there for about 14 hours prior to my questioning.

Defence: So what you are telling me is that you don't remember a lot of it?

Witness: Yes, I guess so.

Defence: Isn't it possible that during this time you forgot some of the details of the crime, including the description of the criminal?

Witness: No, I wouldn't say that.

Defence: Miss Johnson, in your initial description to the police you had reported that the criminal was between $25-30$ years of age, is that correct?

Witness: Yes, that is correct.

Defence: Do you know the actual age of Mr. Sullivan, the defendant?

Witness: Again, I would say between 25-30 years of age.

Defence: Mr. Sullivan is actually 35 -years-old. So you must have been incorrect when you reported the criminal as between $25-30$ years of age?

Witness: I guess so.

Defence: Miss Johnson, how tall are you?

Witness: About 5' 8 ".

Defence: And you stated that the criminal must be around 5'10" because he was taller than you?

Witness: Yes.

Defence: Well Miss Johnson, the defendant who sits here today on trial is in fact 5'7," which is clearly shorter than you. So you were mistaken regarding his height, is that true?

Witness: I'm not sure.

Defence: You also stated in your description of the criminal that he had blue eyes, is that correct?

Witness: Yes, I did.

Defence: Miss Johnson, looking at the defendant, Mr. Sullivan, sitting in this Courtroom can you please tell me the colour of his eyes?

Witness: They look to be brown from here.

Defence: Yes, that is correct. So you must have been mistaken when you stated that the criminal had blue eyes as the defendant clearly has brown eyes?

Witness: Um, I guess so.

Defence: Miss Johnson, you testified that you initially reported to the police that the criminal had a mole on his left cheek?

Witness: Yes, I did.

Defence: Looking at Mr. Sullivan, the defendant on trial, do you see a mole on his left cheek? 
Witness: No, I don't.

Defence: Clearly you were mistaken when you reported the criminal as having a mole on his left cheek?

Witness: I don't know.

Defence: Also, you stated earlier that you described the criminal as having brown hair?

Would you say Mr. Sullivan's hair is brown?

Witness: Well, it looks more blond today.

Defence: So you admit you were wrong when you stated the criminal had brown hair?

Witness: I am just saying that today it looks more blond.

Defence: Miss Johnson, earlier you mentioned that you had also reported to the police that the criminal had shoulder length hair. Would you say the defendant has shoulder length hair?

Witness: Maybe he cut it.

Defence: I did not ask you if he cut his hair, I asked you how long his hair is.

Witness: It is very short, like a brush cut.

Defence: So you must have been mistaken when you stated that the criminal had shoulder length hair?

Witness: Um, I don't know.

Defence: Miss Johnson, in the description you gave to the police, you had stated that the criminal had a goatee.

Witness: Yes, that's correct.

Defence: Does the defendant have a goatee?

Witness: No.

Defence: So you admit that you were wrong when you stated the criminal had a goatee?

Witness: Well, I am just saying that he doesn't have a goatee now.

Defence: Miss Johnson, in your report to the police you also stated that the criminal had a gold earring in his right ear, is that correct?

Witness: Yes.

Defence: Does the defendant have a gold earring in his right ear?

Witness: No.

Defence: Clearly you were mistaken when you described the criminal as having a gold earring in his right ear?

Witness: I'm not sure.

\section{For all transcripts again}

Defence: Miss Johnson, were you ever asked to look at a lineup to identify the criminal? Witness: Yes. A few days after I described the criminal to the police officer, he came back to show me some pictures. He asked me if I recognized the man who shot me. 1. I said yes and picked out number 4 as the criminal (positive ID same as defendant)/2. I said yes and picked out number $\mathbf{4}$ as the criminal (positive ID different than defendant) 3. I said yes and picked out number 2 as the criminal (foil ID defendant in lineup)/4. I said yes and picked out number 2 as the criminal (foil ID defendant not in lineup)/ 5. I did not pick out anyone as the criminal (non-ID defendant in lineup)/ 6. I did not pick out anyone as the criminal (non-ID defendant not in lineup). 
Defence: 1. After you identified him, did the police officer tell you that number 4 was the suspect (positive ID same as defendant)? 2. After you identified him, did the police officer tell you that number 4 was the suspect (positive ID different than defendant)? 3. After you identified him, did the police officer tell you that number 2 was a former police officer that passed away a year ago (foil ID defendant in lineup)? 4. After you identified him, did the police officer tell you that number 2 was a former police officer that passed away a year ago (foil ID defendant not in lineup)? 5. After you did not identify anyone, did the police officer tell you that you missed identifying the suspect (non-ID defendant in lineup)? 6. After you did not identify anyone, did the police officer tell you that you missed identifying the suspect (nonID defendant not in lineup)?

Witness: Yes.

Defence: Was the suspect you identified in the first lineup, the same man as the defendant?

Witness: 1.Yes (positive ID same as defendant). / 2. No (positive ID different than defendant). 3. \& 4. No. I identified an individual who was known to be innocent of the crime (foil IDs defendant in and not in lineup). / 5. \& 6. No. I did not identify anyone from the first lineup (non-IDs defendant in and not in lineup).

\section{For Conditions 2 - 6}

Defence: 2., 3., \& 4. After this first identification decision, did the police call you a week later and ask you to look at another lineup (positive ID different than defendant, foil IDs defendant in and not in lineup)?/ 5. \& 6. After seeing the first lineup, did the police call you a week later and ask you to look at another lineup (non-IDs defendant in and not in lineup)?

Witness: 2., 3., \& 4. Yes. I identified a different man than before (positive ID different than defendant, foil IDs defendant in and not in lineup). 15. \& 6. Yes. This time I identified someone (non-IDs defendant in and not in lineup).

Defence: After you identified him, did the police tell you that you identified the suspect? Witness: Yes.

Defence: 3., 4., 5., \& 6. Was the suspect that you identified this second time present in the first lineup that you viewed? (foil and non-IDs defendants in and not in lineup)

Witness: 4., \& 6. No, he was not. (foil and non-IDs defendant not in lineup) 3. \& 5. Yes, he was. (foil and non- IDs, defendant in lineup)

Defence: Was the suspect that you identified this second time the same man as the defendant?

Witness: Yes.

For all conditions again

Defence: So what you are telling me is that you looked at a lineup and identified the defendant on trial (positive ID same as defendant)? / 2. So what you are telling me is that you looked at a lineup and identified a suspect, but he was not the same man as the defendant on trial. Then later you were asked to look at a second lineup and 
identified the defendant on trial (positive ID different than defendant)? / 3. So what you are telling me is that you looked at a lineup that the defendant was in, but identified an individual known to be innocent. Then later you were asked to look at a second lineup and identified the defendant on trial (foil ID defendant in lineup)? I 4. So what you are telling me is that you looked at a lineup that the defendant was not in, and identified an individual known to be innocent. Then later you were asked to look at a second lineup and identified the defendant on trial (foil ID defendant not in lineup)? / 5. So what you are telling me is that you looked at a lineup that the defendant was in, but did not identify anyone from that lineup. Then later you were asked to look at a second lineup and identified the defendant on trial (non-ID defendant in lineup)? / 6. So what you are telling me is that you looked at a lineup that the defendant was not in, and did not identify anyone from that lineup. Then later you were asked to look at a second lineup and identified the defendant on trial (non-ID defendant not in lineup)?

Witness: Yes, that is correct.

Defence: Thank you. No further questions.

The Witness is excused.

The Defence calls their first witness, Joseph Sullivan (the defendant), and he takes the stand.

Defence: Can you please state your full name for the Court?

Witness: My name is Joseph Sullivan.

Defence: Mr. Sullivan, do you have a criminal record?

Witness: No, I do not.

Defence: Do you now or have you ever owned a firearm?

Witness: No, never.

Defence: Have you ever been to the LCBO at the Glendale Street Plaza?

Witness: Yes, a couple of times.

Defence: Were you there on the night of December 12, 2007 ?

Witness: No, I was not.

Defence: Where were you on that evening, from say 8:30pm to 10:00pm?

Witness: At 8:30pm I was watching television in my apartment. Then at about 9:00pm I took my dog for a walk for half an hour because I would be at Lydia's, my neighbour, looking after her son so I wanted to make sure my dog got out beforehand. Then at around 9:30 I came in, had a shower, made myself a sandwich, ate it, and went to Lydia's apartment around 10:00pm.

Defence: Did anyone see you leaving the building when you went for your walk?

Witness: No.

Defence: Did anyone see you re-enter the building?

Witness: No.

Defence: Perhaps you encountered someone you knew during your dog walk?

Witness: No, I went to Wesley Park it is usually pretty empty at night, especially during the cold season. 
Defence: So there is no one to challenge your whereabouts on the evening of December 12,2007 ?

Witness: No, there is not.

Defence: Thank you Mr. Sullivan. No further questions your Honour.

The Crown cross-examines the witness.

Crown: Mr. Sullivan, you live near a major intersection?

Witness: Yes, I do.

Crown: Is it a busy area, lots of people around?

Witness: Yes, usually.

Crown: However, you managed to take your dog to and from the park for half an hour and not see anyone you know?

Witness: Well it is a large city.

Crown: Mr. Sullivan, you know your neighbour Lydia well enough to care for her son. How long had you lived in the building on the day that the attempted murder occurred?

Witness: Almost 4 months.

Crown: Wow, you managed to get to know her fairly quickly for her to allow you to care for her young son?

Witness: Yes.

Crown: You must be very personable?

Witness: I guess...

Crown: But you managed to leave and re-enter your building without encountering anyone you know?

Witness: Yes, I did.

Crown: Mr. Sullivan where were you employed during the month of the robbery?

Witness: I wasn't working.

Crown: So you didn't have a steady income?

Witness: Well I was receiving unemployment. My work is seasonal, I'm in construction. Crown: I imagine you could have definitely benefited from some extra money, especially with Christmas approaching?

Witness: Well who couldn't?

Crown: Please just answer the question Mr. Sullivan.

Witness: Yes, I could.

Crown: No further questions, your Honour.

The witness is excused.

The Crown makes their closing statement.

Crown: Ladies and gentlemen of the jury, what we have here is an open and shut case. Mr. Sullivan was desperate for money and decided that the best possible way to get fast money was to rob a liquor store at gunpoint. When the robbery didn't go as he had planned he shot the cashier causing a brutal gunshot wound and left her there to die. We have heard the testimony of the eyewitness to the event, providing evidence pointing toward the defendant. We have a detailed description of the defendant and evidence that 
the defendant lives near the location of this tragic event and was in the area that evening. More importantly, we have a positive identification from the eyewitness. What more evidence is required? If you consider all of the facts in evidence, you can only find $\mathrm{Mr}$. Sullivan guilty of attempted murder.

\section{The Defence makes their closing statement.}

Defence: Ladies and gentlemen, the Crown would like you to believe that this is an open and shut case, and in fact, it is. If you consider all of the evidence, it indicates that my client is not guilty. This is a case of convenience. The police were pressured to find the offender. My client seemed to match the description generally and as a result was arrested. Try to remember that the witness' description was not perfect. More importantly, the witness had to view several lineups before being able to identify the defendant as the person responsible for the crime in question (for conditions 2-6). Proof of the whereabouts of the defendant is limited to the words of one scared witness pitted against the words of the defendant. Are you willing to convict a man for attempted murder based on what one person thinks she saw? If you weigh all of the evidence before you, everyone will reach the same answer. Mr. Sullivan is not guilty of the charges against him.

The judge provides the law and instructions for the jury.

Judge: Members of the jury, you have heard the testimony from the victim and the defendant. It is now my responsibility to provide you with the law. Mr. Sullivan has been charged with the following:

239.(1) ATTEMPT TO COMMIT MURDER - Every person who attempts by any means to commit murder is guilty of an indictable offence and liable

(a) if a restricted firearm or prohibited firearm is used in the commission of the offence or if any firearm is used in the commission of the offence and the offence is committed for the benefit of, at the direction of, or in association with, a criminal organization, to imprisonment for life and to a minimum punishment of imprisonment for a term of

(i) in the case of a first offence, five years, and

(ii) in the case of a second or subsequent offence, seven years;

(a.1) in any other case where a firearm is used in the commission of the offence, to imprisonment for life and to a minimum punishment of imprisonment for a term of four years; and (b) in any other case, to imprisonment for life.

Please take into consideration all the information you have heard today, and do not let any biases you may have come into your decision making process.

Please proceed to the next section and answer questions based on what you have read. 


\section{Appendix B}

\section{Verdict Form (continuous)}

Please answer the following question in regards to the testimony you have just read.

1. Based on the information provided in the transcript, how do you find the defendant with respect to the attempted murder of Diane Johnson? Please indicate a number between 1 and 100, with 1 being "Not Guilty" and 100 being "Guilty."

Verdict Number: 


\section{Appendix C}

Reliability, Credibility, and Accuracy Ratings Form

Your Age
Your Gender
Your Ethnicity
Your Primary Language

Please rate how reliable you perceive the testimony, by the eyewitness, Diane Johnson that you just read. Please circle your rating for each question.

1. How reliable was Diane Johnson's overall description of the criminal?

$1 \ldots \ldots 10 \ldots \ldots 20 \ldots \ldots 30 \ldots \ldots$
Not Reliable
$\begin{gathered}\text { Moderately } \\ \text { Reliable }\end{gathered}$

2. How reliable was Diane Johnson's identification of the defendant in court?

\begin{tabular}{|c|c|}
\hline $1 \ldots \ldots 10$. & $\ldots .50 \ldots \ldots$ \\
\hline Not Reliable & Moderately \\
\hline
\end{tabular}

3. How reliable was the identification decision that Diane Johnson made when looking at the first photo lineup, prior to testifying in court?

$1 \ldots \ldots .10 \ldots \ldots . .20 \ldots \ldots .30$

Not Reliable
$40 \ldots . . .50$

Moderately

Reliable
60

70.

80

90.

Absolutely

Reliable

4. How reliable was the identification decision that Diane Johnson made when looking at the second photo lineup, prior to testifying in court? (ID Conditions 2-6 Only)

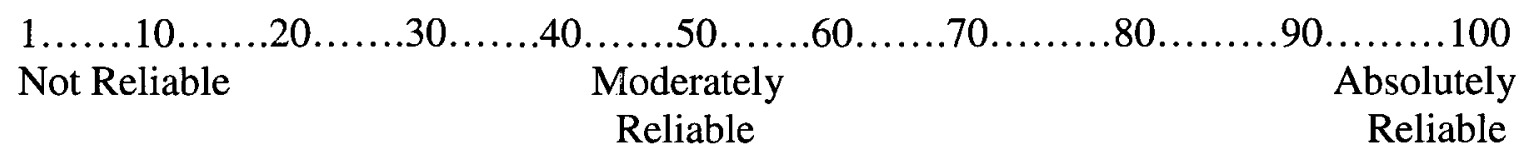

5. How reliable was Diane Johnson's testimony overall?

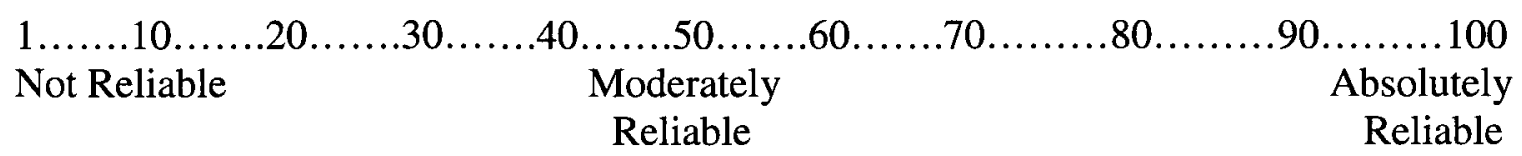


6. How credible was Diane Johnson overall?

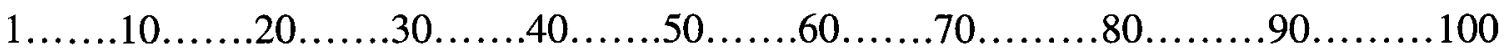
Not Credible Moderately Credible Absolutely Credible

7. How accurate was Diane Johnson overall?

$1 \ldots \ldots . .10 \ldots \ldots .20 \ldots \ldots 30 \ldots \ldots .40 \ldots \ldots .50 \ldots \ldots .60 \ldots \ldots .70 \ldots \ldots \ldots 80 \ldots \ldots \ldots 90 \ldots \ldots \ldots 100$ Not Accurate Moderately Absolutely Accurate Accurate 


\section{Appendix D}

\section{Manipulation Check Form}

Please circle the best answer for each of the following questions.

1. How many descriptor items provided in Diane Johnson's initial description of the criminal to the police were inconsistent with the description of the defendant in court?
a. 2 descriptors
b. 4 descriptors
c. 8 descriptors

2. Based on the information provided in the transcript, how consistent was Diane Johnson's initial description of the criminal to the police in comparison to the description of the defendant in court?

$1 \ldots \ldots 10 \ldots \ldots 20 \ldots \ldots .30 \ldots \ldots 40 \ldots \ldots$
$\begin{gathered}\text { Moderately } \\ \text { Consistent }\end{gathered}$ $\begin{array}{r}\text { Absolutely } \\ \text { Consistent }\end{array}$

3. What was the identification decision made by Diane Johnson when shown the first photo lineup?

a. Diane identified the suspect who was also the defendant

b. Diane identified the suspect who was different than the defendant

c. Diane identified a person known to be innocent of the crime and the defendant was in the lineup

d. Diane identified a person known to be innocent of the crime and the defendant was not in the lineup

e. Diane did not identify anyone and the defendant was in the lineup

f. Diane did not identify anyone and the defendant was not in the lineup

4. Based on the information provided in the transcript, how accurate was the identification decision made by Diane Johnson when shown the first photo lineup?

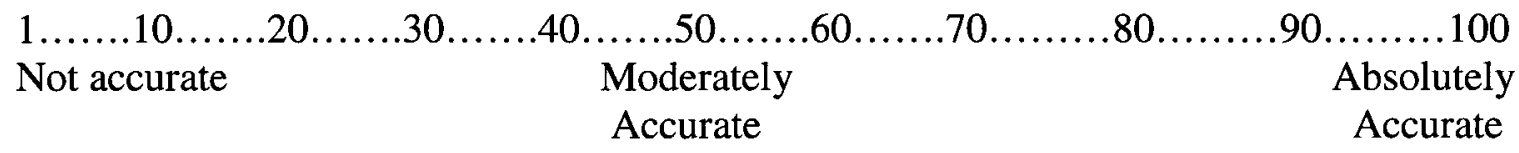

5. What was the identification decision made by Diane Johnson when shown the second photo lineup? (ID Conditions 2-6 Only)

a. Diane identified the suspect who was also the defendant

b. Diane identified the suspect who was different than the defendant

c. Diane identified a person known to be innocent of the crime and the defendant was in the lineup 
d. Diane identified a person known to be innocent of the crime and the defendant was not in the lineup

e. Diane did not identify anyone and the defendant was in the lineup

f. Diane did not identify anyone and the defendant was not in the lineup

6. Based on the information provided in the transcript, how accurate was the identification decision made by Diane Johnson when shown the second photo lineup? (ID Conditions 2-6 Only)

1 ......10 ......20......30......40......50

Not accurate
Moderately

Accurate
$.60 \ldots . . .70$

$70 \ldots \ldots . . .80$

90.

Absolutely 100 Accurate 


\section{Appendix E}

\section{Informed Consent Form}

The purpose of an informed consent is to ensure that you understand the purpose of the study and the nature of your involvement. The informed consent must provide sufficient information such that you have the opportunity to determine whether you wish to participate in the study.

Present Study. An Examination of Juror Decisions.

Research Personnel. The following people are involved in this research project and may be contacted at any time: Monica O'Neill (Principal Investigator, 520-2600, Ext. 3695); Dr. Joanna Pozzulo (Faculty Sponsor, 526-2600, Ext. 1412); Julie Dempsey (Lab Coordinator, 520-2600, Ext. 3695).

Departmental Contacts. Should you have any ethical or other concerns about this study, please contact, Dr. Parush (Chair, Carleton University Research Ethics Committee for Psychological Research, 520-2600, Ext.6026) or Dr. Mantler (Chair, Dept. of Psychology, 520-2600, Ext.4173).

Purpose. The purpose of this study is to examine juror decision-making in a crime concerning an attempted murder in a liquor store robbery.

Task Requirements. You will be requested to read a transcript from a trial involving the testimony of an eyewitness' account of an attempted murder in the commission of a liquor store robbery. You will be asked to answer some questions based on the information you read in the transcript and render a verdict. You have the right not to answer any specific questions without academic penalty.

Duration and Locale. The experimental session will take approximately 45 minutes and will take place in Room SR111, Social Sciences Research Building (SSRB), Carleton University.

Potential Risk/Discomfort. There are no potential physical or psychological risks involved in this experiment.

Anonymity/Confidentiality. The data gathered in this study are confidential and will only be used by researchers associated with this project. No one else will have access to this information. All of the data collected and informed consent forms will remain locked in Dr. Pozzulo's laboratory. Your personal identity will remain anonymous, and none of your contributions will be recognizable in any way. All data will be identified by a participant number only, and the informed consent forms will be stored separately from the data. Information collected will be reported in a general way. 
Right to Withdraw. You may withdraw from the study at any time without academic penalty.

Signatures: I have read the above form and understand the conditions of my participation. My participation in this study is voluntary, and if for any reason, at any time, I wish to leave the experiment I may do so without having to give an explanation and with no penalty whatsoever. Furthermore, I am also aware that the data gathered in this study are confidential and anonymous with respect to my personal identity. My signature indicates that I agree to participate in the study.

Participant's Name: Participant's Signature:

Researcher's Name: Researcher's Signature:

Date: 


\section{Appendix F}

\section{Debriefing Form}

We would like to thank you for your participation in this study. Your participation will help us further our understanding of how jurors' perceptions of witness reliability, accuracy, and credibility may be varied, thus adding to the body of knowledge currently existing in this field.

In many criminal investigations, witnesses are asked to identify the criminal in a lineup. A positive identification occurs when the witness chooses the individual who is suspected to have committed the crime. If the witness chooses an individual that is known to be innocent of that particular crime, then a foil identification decision has been made. These foils are the people in the lineup that are used as "distracters" and known to be innocent for the crime in question. If the witness rejects the lineup, failing to identify any of the individuals in the lineup as the criminal, then a non-identification has occurred.

In criminal trials witnesses will identify the defendant as the individual who committed the crime in question. However, the defence and other members of the court are often unaware that the witness was shown several lineups prior to being able to make this identification. Often the witness made several errors in identifying the suspect, or identified a different suspect, prior to identifying the defendant in court. For example, in $R$. vs. Sophonow (1986), one of the key witnesses was unable to identify Sophonow when shown a lineup prior to court. Later, this witness was arrested for non-payment of a fine and saw Sophonow, who was in the same building for his court appearance. The witness was shown Sophonow as the man accused for the murder of Barbara Stoppel and it was not until after this incident that he was able to identify Sophonow during trial.

Throughout an investigation eyewitnesses will also undergo multiple interviews from various individuals (i.e., police investigators, attorneys, etc.). Witnesses may change their stories or recall new information initially not remembered. Subsequently in the trial, witnesses may provide inconsistent information in their testimony to the court. However, often the court members are unaware that the witness has made previous contradictory statements, or there is other evidence which contests this testimony. In this specific study we examined description inconsistencies with respect to the witness' initial description of the criminal and the appearance of the defendant in court.

The purpose of the proposed study is to investigate how jurors' knowledge of inconsistent identification decisions and inconsistent criminal descriptions made prior to trial will influence perceived accuracy, reliability, and credibility of a witness and therefore subsequent verdicts. This study is unique because often jurors are only aware of identification decisions that are made in the courtroom or when a positive identification of the suspect was made after viewing multiple lineups and making different decisions. The Crown often omits the fact that witnesses have viewed several lineups and made several incorrect or different decisions prior to actually being able to identify the suspect or defendant. 
The trial transcript used in this study was fictional and designed solely for the purpose of the present study. Therefore there is no actual verdict for this particular case.

We are grateful for your participation in this study. If you would like to discuss any of this research further, please contact any of the following people: Monica O'Neill (Principal Investigator, 520-2600, Ext. 3695); Dr. Joanna Pozzulo (Faculty Sponsor, 5262600, Ext. 1412); Julie Dempsey (Lab Coordinator, 520-2600, Ext. 3695).

If you have any ethical concerns regarding the present study please contact Dr. Parush (Chair, Carleton University Research Ethics Committee for Psychological Research, 520-2600, Ext.6026) or Dr. Mantler (Chair, Dept. of Psychology, 520-2600, Ext.4173). 